\title{
可见光诱导烷基羧酸及其衍生物的脱羧偶联反应研究进展
}

\author{
周明东* 覃不涛经理珂孙京* 杜海武 \\ (辽宁石油化工大学化学化工与环境学部 辽宁抚顺 113001)
}

\begin{abstract}
摘要 烷基羧酸广泛存在于自然界之中, 科研工作者一直致力于开发以来源丰富的烷基羧酸及其衍生物作为起始原料 的反应. 烷基羧酸及其衍生物在可见光氧化还原作用下可以高效地生成烷基自由基，从而在温和条件下用于构筑各类 化学键. 以可见光催化烷基羧酸及其衍生物的脱羒自由基反应类型为线索, 系统地综述了近年来在可见光条件下烷基 羧酸及其衍生物的脱羧官能团化反应研究进展.
\end{abstract}

关键词 可见光催化; 脱羧反应; 烷基自由基

\section{Progress in Photoinduced Decarboxylative Radical Cross-Coupling of Alkyl Carboxylic Acids and Their Derivatives}

\author{
Zhou, Mingdong* Qin, Pitao Jing, Like Sun, Jing* Du, Haiwu \\ (College of Chemistry, Chemical Engineering and Environmental Engineering, Liaoning Shihua University, \\ Fushun, Liaoning 113001)
}

\begin{abstract}
Alkyl carboxylic acids are among the most ubiquitous organic molecules found in nature. The reactions using abundant carboxylic acid and its derivatives as starting materials deserve widespread attention over the world. They are often easy to generate alkyl radical by photoredox catalysis under mild conditions for building various chemical bonds in organic chemistry. Based on the reaction modes, decarboxylation of alkylcarboxylic acids and their derivatives, the recent progress in decarboxylation of alkylcarboxylic acids and their derivatives under visible light is reviewed.

Keywords photocatalysis; decarboxylative; alkyl radical
\end{abstract}

羧酸及其衍生物广泛地存在于自然界之中，具有来 源丰富和、稳定性好等特点, 利用羧酸作为起始原料构 筑各类有机分子已经成为有机合成化学中的热门研究 领域之一 ${ }^{[1 \sim 3]}$. 自由基反应是有机化学中非常重要的反 应，其中可见光诱导的自由基反应已经成为构筑各类化 学键的有效合成策略 ${ }^{[4 \sim 6]}$. 烷基羧酸及其衍生物在可见 光作用下脱去一分子二氧化碳形成烷基自由基, 而生成 的烷基自由基可以进行一系列后续转化, 提供了一条经 由脱羧自由基官能团化制备有机分子的合成路线 ${ }^{[7 ~ 9]}$. 可见光反应体系一般具有反应活性高、条件温和、官能 团容忍性好及底物适用范围广等优点. 本文按照可见光 作用下烷基羧酸及其衍生物形成烷基自由基的后续反 应类型进行分类, 对烯烃/炔烃加成、加成环化、芳杂环
加成、自由基偶联、有机金属(M-R)交叉偶联及其它反 应进行了归纳和总结.

在可见光氧化还原催化体系下, 烷基羧酸在碱的作 用下经历单电子氧化过程失去一个电子, 脱除一分子二 氧化碳形成烷基自由基. 与此同时, 烷基羧酸通过简单 的酯化反应，能够制备具有良好氧化活性的烷基 $N$-差 基邻苯二甲酰亚胺酯, 其在可见光催化体系经历单电子 还原过程得到一个电子, 随后脱除二氧化碳形成烷基自 由基(Scheme 1). 在可见光氧化还原体系烷基羧酸及其 衍生物可以分别经历氧化和还原过程得到烷基自由基, 这吸引了广大科研工作者的兴趣, 极大地促进了可见光 诱导脱羧自由基反应的发展，丰富了烷基羧酸及其衍生 物在可见光催化领域的应用.

\footnotetext{
* Corresponding authors. E-mail: mingdong.zhou@Inpu.edu.cn; sungjing@lnpu.edu.cn Received September 18, 2019; revised November 1, 2019; published online December 2, 2019. Project supported by the Doctoral Start-up Foundation of Liaoning Province (No. 20180540085). 辽宁省自然科学基金博士启动(No. 20180540085)资项目.
} 


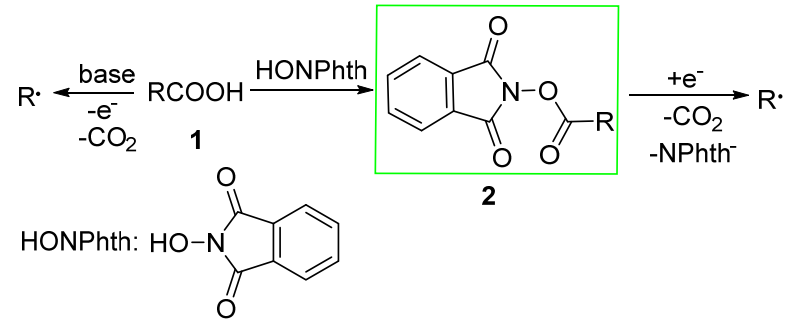

图式 1 烷基羧酸及其衍生物脱羧过程

Scheme 1 Decarboxylative of alkyl carboxylic acids and their derivatives

\section{1 烯烃及炔烃加成反应}

烷基羧酸及其衍生物在可见光条件下能够高效地 形成烷基自由基, 通过自由基对不饱和键的加成反应构 筑各类化学键是自由基化学经典的反应过程. 烷基自由 基对烯烃/炔烃的加成反应可能形成烷基化、烯基化、炔 基化与双官能团化产物四种类型产物.

\section{1 自由基烷基化}

可见光促进的烷基羧酸及 $\alpha$-氨基酸的脱羧自由基 加成反应近年来受到了广泛关注, MacMillan 课题组 ${ }^{[10]}$ 报道了可见光促进的烷基羧酸与缺电子烯烃的 Michael 加成反应(Scheme 2). 在可见光的照射下铱催化剂进入 到激发态, 而激发态的铱催化剂具有强氧化能力, 其单 电子氧化环己羧酸并脱除二氧化碳得到环己基自由基, 环己基自由基与缺电子烯烃 $\mathbf{3}$ 加成构建新的碳-碳键形 成自由基物种 $\mathbf{5}$, 随后经过单电子还原得到 1,4-加成产

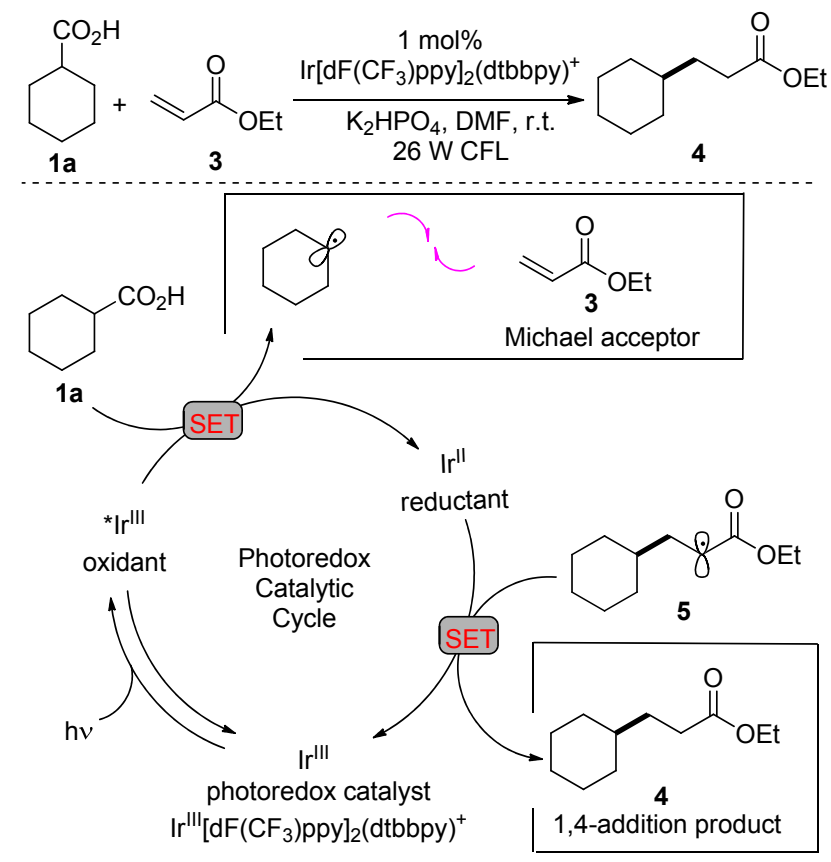

图式 2 脱羧共轭加成反应

Scheme 2 Decarboxylative conjugate addition
物 4. 值得注意的是, 利用这种新型的脱羧加成策略可以 简单地通过三步法合成药物分子 pregabalin. Nishibayashi 课题组 ${ }^{[11]}$ 在可见光条件下以对位氨基取代的苯乙酸作 为苄基化试剂, 实现了茮基自由基对缺电子烯烃的加成 反应. Ruepling 课题组 ${ }^{[12]}$ 研究了氨基酸在可见光作用下 形成的一级及二级氨甲基自由基与不饱和羰基化合物 的加成反应. Gonzalez-Gomez 及 Koike 等 ${ }^{[13,14]}$ 研究了可 见光非金属鲐啶盐类催化剂的脱羧反应体系. 近来, MacMillan 课题组 ${ }^{[15]}$ 将此可见光促进的脱羧自由基反应 策略运用于蛋白质的选择性位点修饰, 成功地实现了胰 岛素蛋白质的选择性修饰，提供了一种全新的生物共轭 加成方法, 将促进蛋白质修饰领域的快速发展. Flanagan 等 ${ }^{[16]}$ 开发了 DNA 标记的自由基受体与 $\alpha$-氨基酸的自由 基加成反应体系. 而 $\alpha$-酮酸经历脱羧基及脱羰基过程, 亦能高效形成烷基自由基, 并与烯烃发生加成反 应 ${ }^{[17]}$.

烷基羧酸作为自由基前驱体与含有杂原子烯烃化 合物加成，能够制备各类具有高附加值的有机化合物. $\alpha$-三氟甲基炔烃常用来合成各类有机氟化物，周䂞等 ${ }^{[18]}$ 报道了可见光诱导的 $\alpha$-氨基酸与 $\alpha$-三氟甲基炔烃 $\mathbf{6}$ 的脱 羧/脱氟反应(Scheme 3), 在温和反应条件下高效地合成 了一系列偕二氟类化合物 7 和 $\mathbf{8}$, 并且这些化合物能够 进一步转化为具有高附加值的二氟甲基化合物或单氟 杂环化合物，该反应具有良好的底物普适性，多种 $\alpha$-酮 酸和 $\alpha$-氨基酸均能以中等到良好的收率获得偕二氟类 化合物. 嗍酸及其衍生物在有机合成、高分子材料及医 药行业都有十分重要的作用, Aggarwal 课题组 ${ }^{[19]}$ 报道了 可见光条件下 $\alpha$-氨基羧酸与烯基嶰酸酯 9 的脱羧自由基 加成反应，高效地制备一系列 $\gamma$-氨基嗍酸酯化合物 10 (Eq. 1). 他们通过氝代标记实验和密度泛函(DFT)理论 计算认为, 该反应涉及 $\alpha$-硼自由基的单电子还原过程, 由于烷基硼酸酯可以发生一系列后续官能团化，这种高 效合成烷基硼酸酯方法对药物的开发具有重要的价值. $\alpha$-芳基烯基膦酸酯表现出良好的生物学活性, 李燕等 ${ }^{[20]}$ 研究了可见光条件下烷基羧酸与 $\alpha$-芳基烯基膦酸酯 $\mathbf{1 1}$ 的 Giese 反应，简单高效地制备了 $\alpha$-芳基烷基膦酸酯化合物 12 (Eq. 2), 反应具有良好的官能团容忍性和底物普适性, 还可以用于制备 $\alpha$-芳基取代的膦胺霉素类似物.

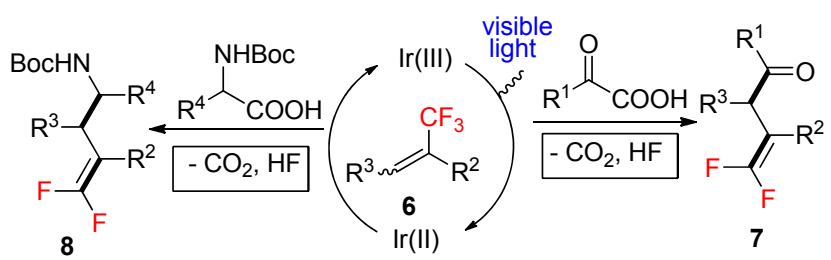

图式 3 可见光催化脱羧/脱氟反应

Scheme 3 Photocatalytic decarboxylative/defluorinative reaction 
<smiles>O=C(O)C1CCCN1</smiles>

1b

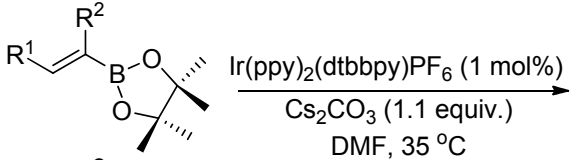

$40 \mathrm{~W}$ blue LED lamp<smiles>[R]C(OB(OC([R])(C)C)C([R])(C)C)C1CCCN1</smiles>

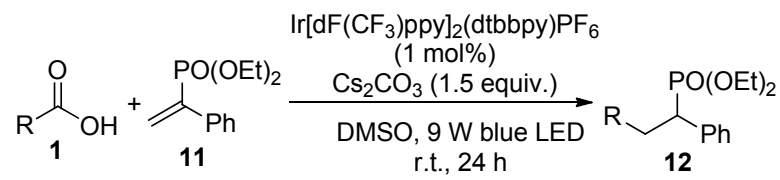

可见光促进的自由基手性合成一直是有机光化学 中最具有挑战性的课题之一, 江智勇等 ${ }^{[21]}$ 开发了可见 光催化剂二腈基哌嗪化合物(DPZ), 结合手性磷酸的协 同催化体系, 实现了 $N$-芳基甘氨酸与 $\alpha$-支链-2-烯基吡 啶/喹啉类化合物 13 的非对映选择性自由基加成 (Scheme 4). 在温和反应条件下以良好的收率及优异的 对映选择性制备了一系列具有高附加值的手性 $\alpha$-叔碳 芳杂烃化合物 15. 他们认为手性来源于氢键作用下的 立体选择性氢质子化, 此外该反应被成功地应用于 $(R)-$ 非尼拉敏药物分子制备.
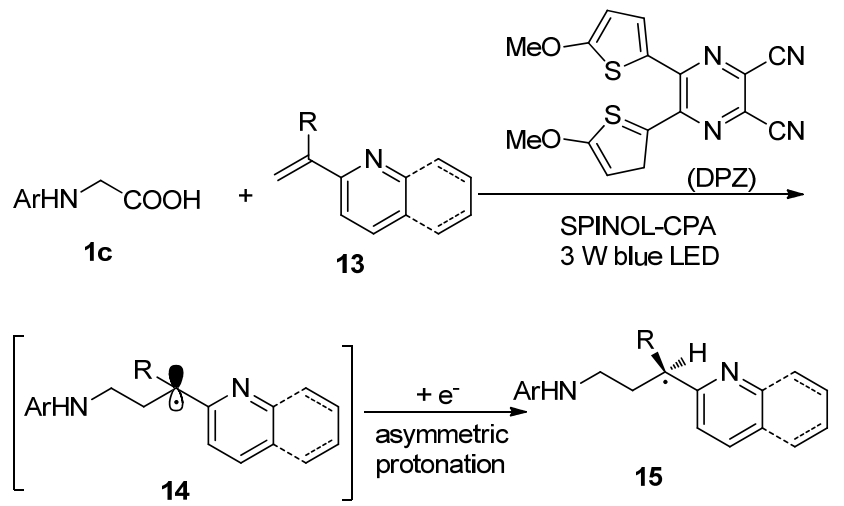

图式 4 手性共轭加成

Scheme 4 Conjugate addition-enantioselective

烷基羧酸的酯化产物烷基 $N$-羟基邻苯二甲酰亚胺 酯的脱羧烷基化反应近来受到了人们的关注, 早在 1991 年, Okada 等 ${ }^{[22]}$ 报道了在可见光作用下烷基 $N$-羟基 邻苯二甲酰亚胺酯 $\mathbf{2}$ 与缺电子烯烃 16 的 Michael 加成反 应(Eq. 3). 烷基 $N$-羊基邻苯二甲酰亚胺酯在可见光催化 剂 $\left[\mathrm{Ru}(\mathrm{bpy})_{3}\right] \mathrm{Cl}_{2}$ 及氢给体 1-芐基-1,4-二氢烟酰胺(BNAH) 的作用下, 通过单电子转移过程脱去二氧化碳形成烷基 自由基, 随后与缺电子烯烃加成得到主产物 17. 由此可 见, 烷基 $N$-羟基邻苯二甲酰亚胺酯可以作为良好的烷 基自由基前驱体. 然而直到近年来可见光促进的脱羧自
由基体系才得以快速发展，Overman 与合作者 ${ }^{[23]}$ 报道了 在可见光作用条件下烷基 $N$-羟基邻苯二甲酰亚胺酯高 效形成三级烷基自由基，随后与不饱和烯烃发生自由基 加成反应，从而高效构建四级碳中心分子，此反应体系 被成功地应用于天然产物二萜化合物 aplyviolene (21)的 全合成(Scheme 5). 随后, 他们 ${ }^{[24]}$ 将烯烃偶联试剂拓展 到烯丙基和乙烯基卤代化合物，这些化合物都能很好地 兼容该反应体系, 但是反应速率稍微变慢. 陈以昀 ${ }^{[25]}$ 以 烯基砜化合物为烯基化试剂，完成了类似的反应，反应 具有非常好的底物普适性，适用于一级、二级、三级、 芐基与 $\alpha$-杂原子取代的活性酯，而且反应不仅可以在有 机溶剂中发生, 在中性水溶液中也能很好地进行.
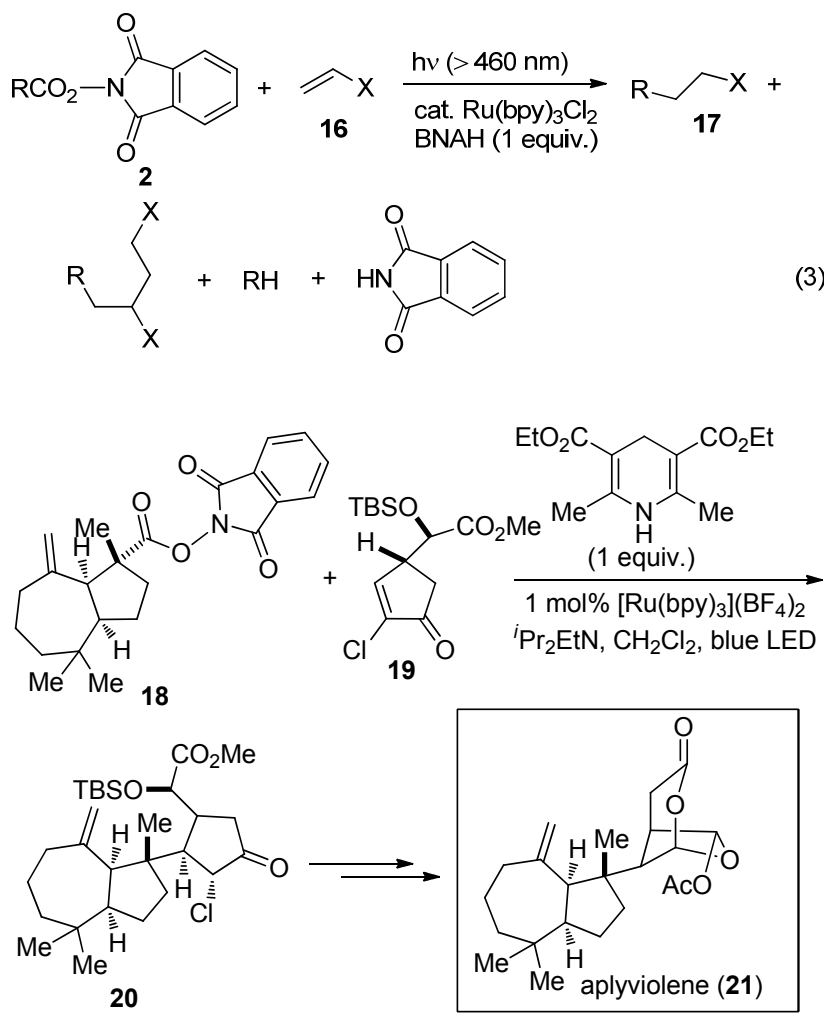

图式 5 Aplyviolene 的全合成

Scheme 5 Total synthesis of aplyviolene

2016 年, König 课题组 ${ }^{[26]}$ 报道了由来源丰富的氨基 酸及脂肪酸通过简单的酯化反应制备一系列烷基 $N$-羊弪 基邻苯二甲酰亚胺酯, 其在有机染料光催化剂曙红的作 用下高效地形成烷基自由基，随后与缺电子烯烃 22 发 生加成反应(Eq. 4). 该反应体系展现出良好的底物普适 性，适用于 $\alpha$-氨基酸和 $\alpha$-酩酸及(一级、二级及三级)脂 肪酸，但是对于自然界中广泛存在的长链脂肪酸衍生 物, 产率都相对偏低. 付华课题组 ${ }^{[27]}$ 使用廉价易得的苯 硫酚类化合物作为光催化剂, 实现了烷基 $N$-着基邻苯 二甲酰亚胺酯与缺电子烯烃 $\mathbf{2 4}$ 的脱羧自由基加成反应 (Eq. 5)，其中 4-三氟甲基苯硫酚表现出最佳的光催化性 
能. 利用丰富的苯硫酚类化合物作可见光催化剂能够有 效地降低反应成本, 值得注意的是, 该反应体系同样适 用于烷基 $N$-羟基邻苯二甲酰亚胺酯自身脱羧胺化, 及 其与异氰联苯的环化反应.
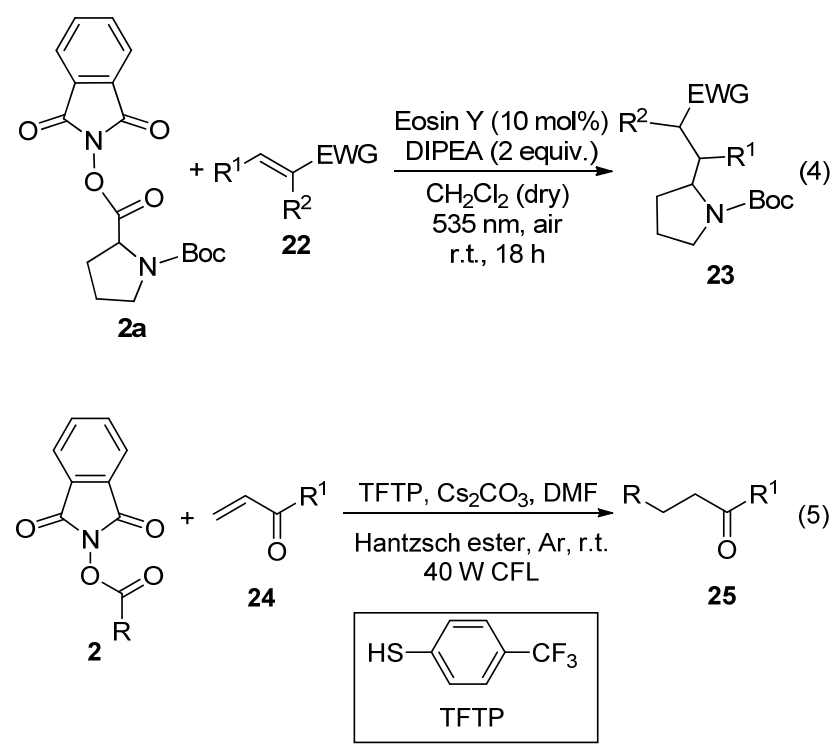

\section{2 自由基烯基化}

与简单烯烃的烯基化反应是有机化学重要的反应 之一，其中 Heck 反应已经成为有机合成中的基本反应. 近来自由基与烯烃的直接加成制备烯基化产物受到了 关注, 相比传统 Heck 烯基化反应, 该反应是通过自由 基对烯烃加成后继续氧化得到烯基化产物. MacMillan 课题组 ${ }^{[28]}$ 报道了可见光条件下 $\alpha$-氨基酸与烯基砜化合 物 26 的脱羧烯基化反应, 合成了一系列烯丙胺化合物 27 (Scheme 6). 在可见光氧化还原体系下 $\alpha$-氨基酸经历 脱羧过程形成了 $\alpha$-氨甲基自由基, 其与烯基砜加成释放 出芳基砜自由基并且得到烯基化产物，而释放的芳基砜 自由基氧化 $\operatorname{Ir}(\mathrm{II})$ 至 $\operatorname{Ir}(\mathrm{III})$, 从而实现整个可见光催化循 环. 这种具有优异几何构型的反应体系被成功地应用
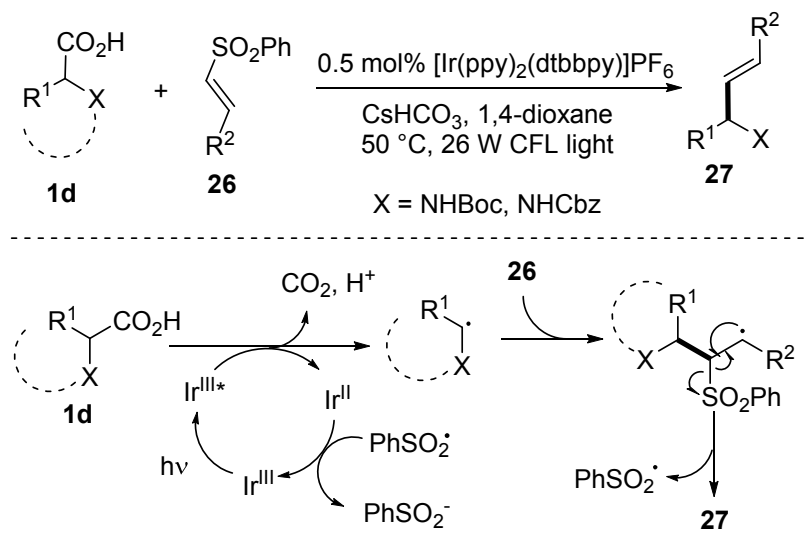

图式 6 脱羧烯基化反应

Scheme 6 Decarboxylative vinylation
于各种天然产物和医药分子的合成.

1,2-二取代的烯烃化合物是一类重要的有机合成 子, 吴杰课题组 ${ }^{[29]}$ 报道了可见光催化剂高氯鲐啶盐与 钴催化剂的协同催化体系下烷基羧酸的 Heck 型交叉偶 联反应(Scheme 7), 通过控制实验和 DFT 理论计算，他 们认为反应涉及自由基历程，而通过钴与可见光结合的 协同作用避免了额外氧化剂的使用，只产生氢气和二氧 化碳副产物，提升了反应的清洁性. 该反应高效地制备 了一系列烯基硅烷、烯基喼酸酯及三组分偶联烯基化合 物，有利于开发更多具有高附加值的二取代烯基化产物 及药物分子后期的功能化修饰. 那日松等 ${ }^{[30]}$ 研究了可 见光和过渡金属钯协同催化的烷基羧酸与苯乙烯类化 合物的 Heck 偶联反应，作者认为反应经历铱催化剂的 能量转移和电子转移及钯催化 $\beta-\mathrm{H}$ 消除和插入等过程, 高效地制备了一系列具有专一 $Z$-选择性的 $\beta$-烷基化苯 乙烯衍生物, 然而一级脂肪酸和 $\alpha$-氧烷基羧酸则不能适 用于该催化体系. MacMillan 课题组 ${ }^{[31]}$ 研究了可见光和 镍协同催化烷基羧酸与非活化炔烃的脱羧氢烷基化反 应，制备了各类功能化烯烃化合物.

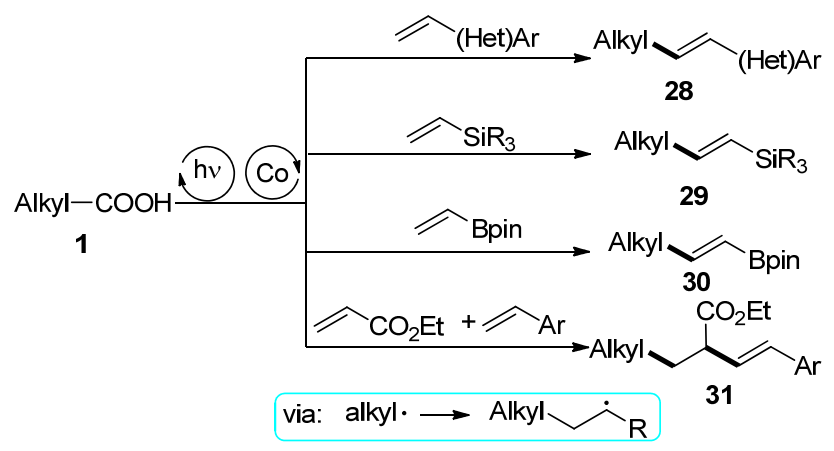

图式 7 烷基羧酸的 Heck 型脱羧偶联

Scheme 7 Decarboxylative Heck-type coupling of aliphatic carboxylic acids

烷基 $N$-羟基邻苯二甲酰亚胺酯作为烷基自由基前 驱体的脱羧烯基化反应也受到了关注(Scheme 8), 段新 华等 ${ }^{[32}$ 报道了在可见光条件下 $N$-羟基邻苯二甲酰亚胺 酯与不饱和烯基羧酸 32 经历双脱羧过程的偶联反应, 反应以 $f a c-\operatorname{Ir}(\mathrm{ppy})_{3}$ 作可见光催化剂, 添加剂 $\mathrm{Mg}\left(\mathrm{ClO}_{4}\right)_{2}$ 能够显著提高反应的收率. 通过自由基捕获和自由基钟 实验，他们认为反应体系可能涉及烷基自由基过程，该 反应具有良好的底物普适性, 适用于一级、二级和三级 烷基羧酸酯. 几乎同时, 徐坤等 ${ }^{[33}$ 报道了以 $\mathrm{Ru}(\mathrm{bpy})_{3} \mathrm{Cl}_{2}$ • $6 \mathrm{H}_{2} \mathrm{O}$ 作可见光催化剂 $N$-差基邻苯二甲酰亚胺酯与烯基 羧酸的双脱羧偶联反应，1,4-二氮杂二环 [2.2.2]辛烷 $(\mathrm{DABCO})$ 在反应中不仅作为碱, 还是单电子转移的共 催化剂. 傅尧等 ${ }^{[34]}$ 发现 $\mathrm{Pd}\left(\mathrm{PPh}_{3}\right)_{2} \mathrm{Cl}_{2}$ 与配体 Xantphos 在 蓝色 LED 灯照射下能够高效地催化烷基 $N$-羟基邻苯二 
甲酰亚胺酯与烯基芳烃 34 的脱羧自由基加成反应，在 光照条件下钯络合物通过单电子转移活化烷基 $N$-羟基 邻苯二甲酰亚胺酯，同时抑制烷基钯中间体的 $\beta$ - $\mathrm{H}$ 消除. Glorius 等 ${ }^{[35]}$ 以廉价 $\mathrm{Pd}\left(\mathrm{PPh}_{3}\right)_{4}$ 作为可见光催化剂实现了 烷基 $N$-羟基邻苯二甲酰亚胺酯与烯烃 36 的脱羧 Heck 型偶联反应. 金灿等 ${ }^{[36]}$ 报道了在温和条件下可见光诱 导烷基 $N$-羟基邻苯二甲酰亚胺酯与香豆素 38 的区域选 择性脱羧烷基化反应, 在无需额外氧化剂条件下以中等 到优秀的收率合成了一系列 3-烷基取代的香豆素衍生 物. 唐真宇等 ${ }^{[37]}$ 报道了可见光促进的 $N$-羟基邻苯二甲 酰亚胺酯与末端炔烃 $\mathbf{4 0}$ 的脱羧偶联反应, 高选择性地 得到了一系列 $Z$-选择性的烯烃化合物 41. 鲍红丽等 ${ }^{[38]}$ 研究了可见光与镍协同催化烷基二酰基过氧化物与末 端炔烃的氢烷基化反应.
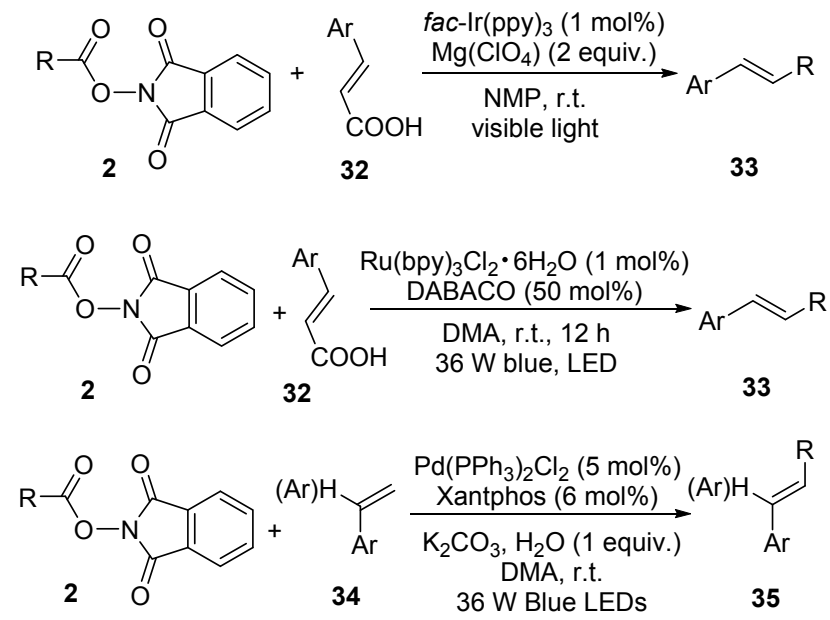<smiles>[R]C=C([Al])[Hg]</smiles>

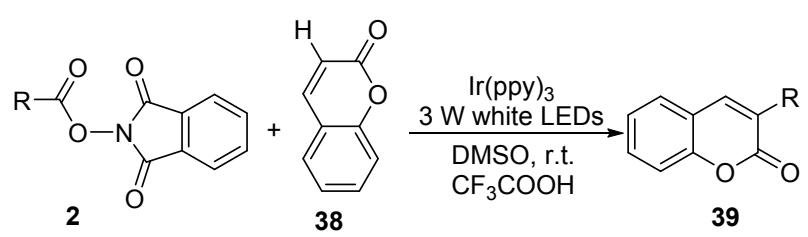

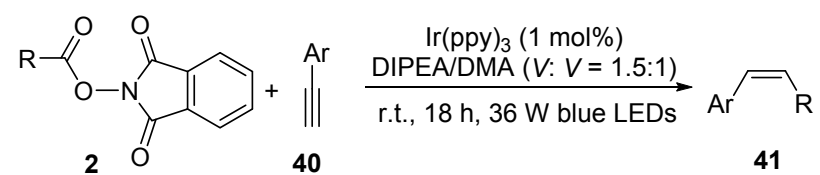

图式 8 烷基 $N$-羟基邻苯二甲酰亚胺酯脱羧烯基化反应 Scheme 8 Decarboxylative coupling of $N$-(acyloxy)phthalimide

\section{3 自由基炔基化}

炔烃是有机合成中一类非常重要的化合物, 通过化 学选择性 $\mathrm{C}\left(\mathrm{sp}^{3}\right)-\mathrm{C}(\mathrm{sp})$ 键偶联反应能够高效地构建炔
烃分子. 其中，自由基型 $\mathrm{C}\left(\mathrm{sp}^{3}\right)-\mathrm{C}(\mathrm{sp})$ 键偶联反应能够 高效地制备内炔化合物，肖文精课题组 ${ }^{[39]}$ 报道了可见 光促进的烷基羧酸与炔基高碘化合物 42 的脱羧炔基化 及羰基炔基化反应(Scheme 9). $\operatorname{Ir}\left[\mathrm{dF}\left(\mathrm{CF}_{3}\right) \mathrm{ppy}\right]_{2}$ (dtbbpy)$\mathrm{PF}_{6}$ 吸收可见光能量后进入到激发态, 烷基羧酸经历单 电子氧化脱除二氧化碳得到烷基自由基，随后发生自由 基加成消除得到目标内炔化合物 43, 若是在 CO 存在条 件下能够得到羰基炔基化合物 44. 反应体系无需额外 的氧化剂，在温和反应条件能够以良好到优秀的产率得 到一系列内炔及羰基炔化合物，与此同时该催化体系被 成功用于天然产物的后期功能化修饰.

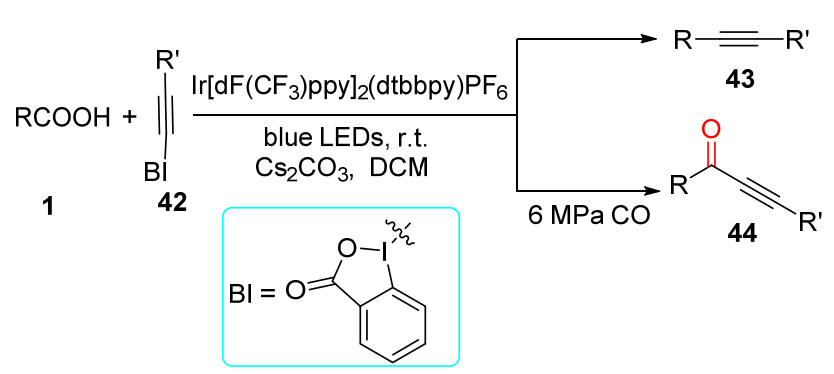

图式 9 脱羧炔基化/羰基炔基化反应

Scheme 9 Decarboxylative alkynylation/carbonylative alkynylation

陈以昀等 ${ }^{[40]}$ 研究了可见光促进的烷基 $N$-羟基邻苯 二甲酰亚胺酯与炔基苯基砜 45 的还原交叉偶联反应 (Eq. 6). 在有机溶剂或中性水溶液条件下可以高效地制 备烷基、芳基及硅基取代的炔烃化合物 46, 值得注意的 是该反应体系兼容各种官能团及生物分子, 并且对蛋白 酶的活性没有任何影响.<smiles>[R]C(=O)ON1C(=O)c2ccccc2C1=O</smiles>

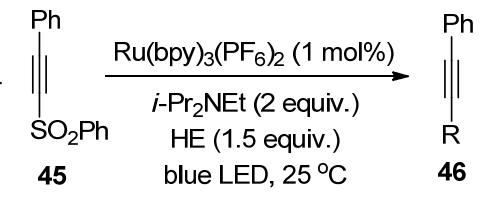

\section{4 双官能团化}

通过烯烃 “一步” 反应同时引入两个双官能团，是 有机反应中一种非常理想的合成策略. Glorius 课题组 ${ }^{[41]}$ 报道了可见光促进的 $N$-羟基邻苯二甲酰亚胺酯、苯乙烯 类化合物 47 与水或醇的多组分偶联反应，通过烯烃的 直接双官能团化高效地制备了一系列复杂的醇或醚化 合物 48. 水或醇与 $N$-羟基邻苯二甲酰亚胺酯通过氢键 作用形成络合物 49, 在可见光氧化下还原体系 49 得到 一个电子形成物种 $\mathbf{5 0}$, 而中间体 $\mathbf{5 0}$ 经历 $\mathrm{N}-\mathrm{O}$ 键断裂 及脱羧形成烷基自由基，随后烷基自由基与烯烃加成形 成新的烷基自由基中间体 51 , 再失去一个电子得到碳 正离子 52, 最后在亲核试剂作用下生成目标化合物 48. 


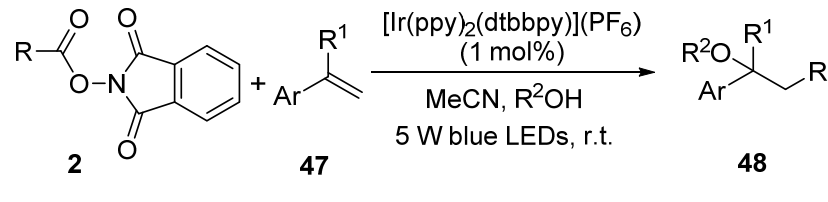

$\mathrm{H}-\mathrm{OR}^{2}$

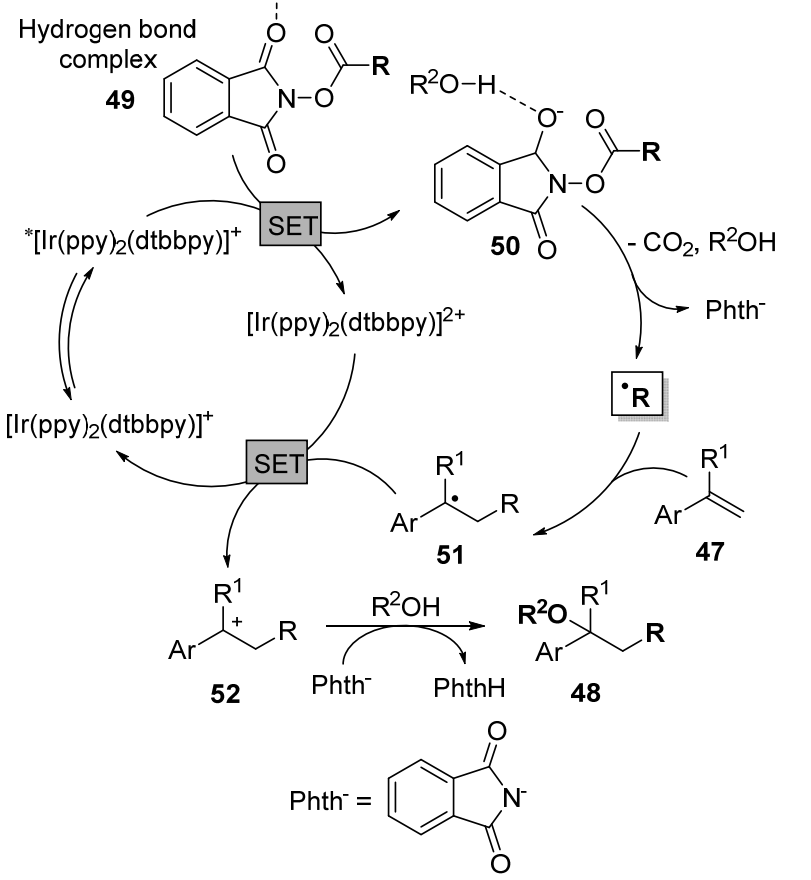

图式 10 可见光诱导苯乙烯类化合物的烷氧基化反应

Scheme 10 Photoinduced oxyalkylation of styrenes

2017 年, 鲍红丽课题组 ${ }^{[42]}$ 研究了可见光诱导的苯 乙烯 53 与烷基二酰基过氧化物 54 的脱羧烷基酯化反应 (Eq. 7). 烷基二酰基过氧化物可以通过来源丰富的烷基 羧酸简单制备, 在可见光氧化还原催化体系下能形成烷 基自由基与烷基羧酸负离子, 在反应体系中既作为烷基 自由基源, 还提供了烷基羧酸官能团, 从而实现了苯乙 烯的双官能团化. 在底物适用性方面, 多种苯乙烯类化 合物及烷基二酰基过氧化物均能高效地转化得到目标 产物, 而反应体系的唯一副产物是二氧化碳气体, 提高 了反应的经济性.

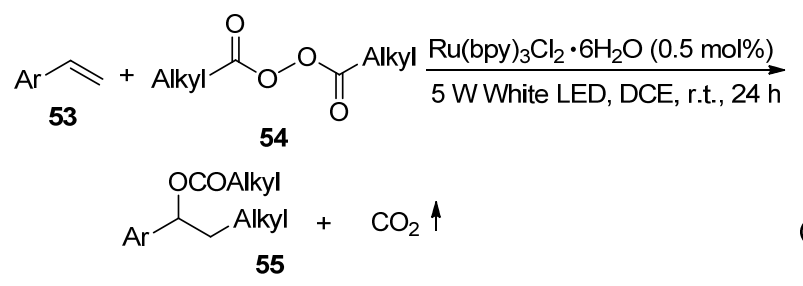

(7)

胺类化合物在有机合成中是一类非常重要的化合 物, 不仅能够作为有机合成子, 其本身还具有独特的生 物学活性, 从而被广泛地应用于医药领域. 胺与烯烃的
直接官能团化是目前构建功能化有机胺化合物强有力 的合成手段, 2018 年, 李金恒课题组 ${ }^{[43]}$ 报道了可见光催 化与路易斯酸协同作用下烷基 $N$-羟基邻苯二甲酰亚胺 酯、烯烃 56 与胺 57 的三组分 1,2-烷基胺化反应(Eq. 8). 在反应体系中 $N$-差基邻苯二甲酰亚胺酯为烷基自由基 源，胺为末端亲核试剂，通过碳一碳键和碳一氮键的高效 构建制备了一系列官能团化的二级与三级胺化合物 58. 该反应体系具有良好的底物普适性，适用于各类苯乙 烯、烷基 $N$-羊隹基邻苯二甲酰亚胺酯及胺化合物，提供了 一条高效制备具有高附加值胺类衍生物的合成路线.<smiles>[R]C(=O)ON1C(=O)c2c[c-]ccc2C1=O</smiles>

2018 年, Glorius 小组 ${ }^{[4]}$ 在可见光条件下通过苯乙 烯 59 氧化烷基化反应制备了一系列 $\alpha$-烷基苯乙酮衍生 物 60 (Eq. 9). $N$-羟基邻苯二甲酰亚胺酯在可见光氧化还 原催化剂作用下脱羧形成烷基自由基，而烷基自由基与 苯乙烯发生加成得到稳定的苄基自由基，随后其被氧化 得到烷基正离子，在二甲基亚砜(DMSO)存在下经历 Kornblum 氧化得到 $\alpha$-烷基苯乙酮, DMSO 不仅作为反应 的溶剂, 还是反应体系的氧源. 与此同时, 叶松课题组 ${ }^{[45]}$ 报道了通过类似的反应过程制备酮类化合物，若在反应 体系中加入三氟甲磺酸, 则形成 Heck 型产物. 宋秋玲课 题组 ${ }^{[46]}$ 报道了可见光促进的 $N$-差基邻苯二甲酰亚胺酯 与芳基烯基硅醚 61 制备烷基苯乙酮 62 的反应(Eq. 10).<smiles>[R]C(=O)ON1C(=O)c2ccccc2C1=[OH+]</smiles>

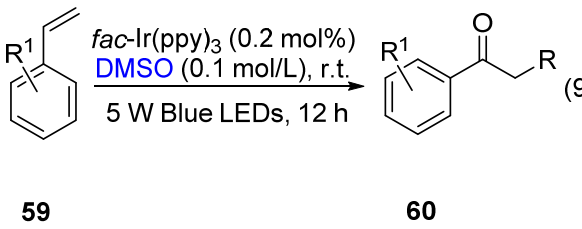<smiles>[R]CC(=O)c1ccc[R1]([R20])c1</smiles> 
手性腈化合物在医药领域具有重要的作用, 2018 年, 韩建林课题组 ${ }^{[4]}$ 利用可见光与铜的协同催化作用 实现了苯乙烯 59 的手性自由基氰烷基化反应，高效地 制备了一系列手性腈类化合物 63 (Scheme 11). 反应的 推测机理如下: $N$-羟基邻苯二甲酰亚胺酯在可见光氧化 还原催化体系中, 高效地形成环成基自由基, 环戊基自 由基与苯乙烯发生自由基加成得到关键的苄基自由基 中间体 64, 与此同时 $\mathrm{Cu}(\mathrm{I})$ 经过氧化得到手性 Box/ $\mathrm{Cu}(\mathrm{II})$, 芐基自由基 64 氧化手性 $\mathrm{Box} / \mathrm{Cu}(\mathrm{II})$ 并与三甲基 氧硅烷(TMSCN) 反应得到手性中间体 $\mathrm{Box} / \mathrm{Cu}(\mathrm{III})$ 物种 65, 最后经过还原消除得到目标化合物.
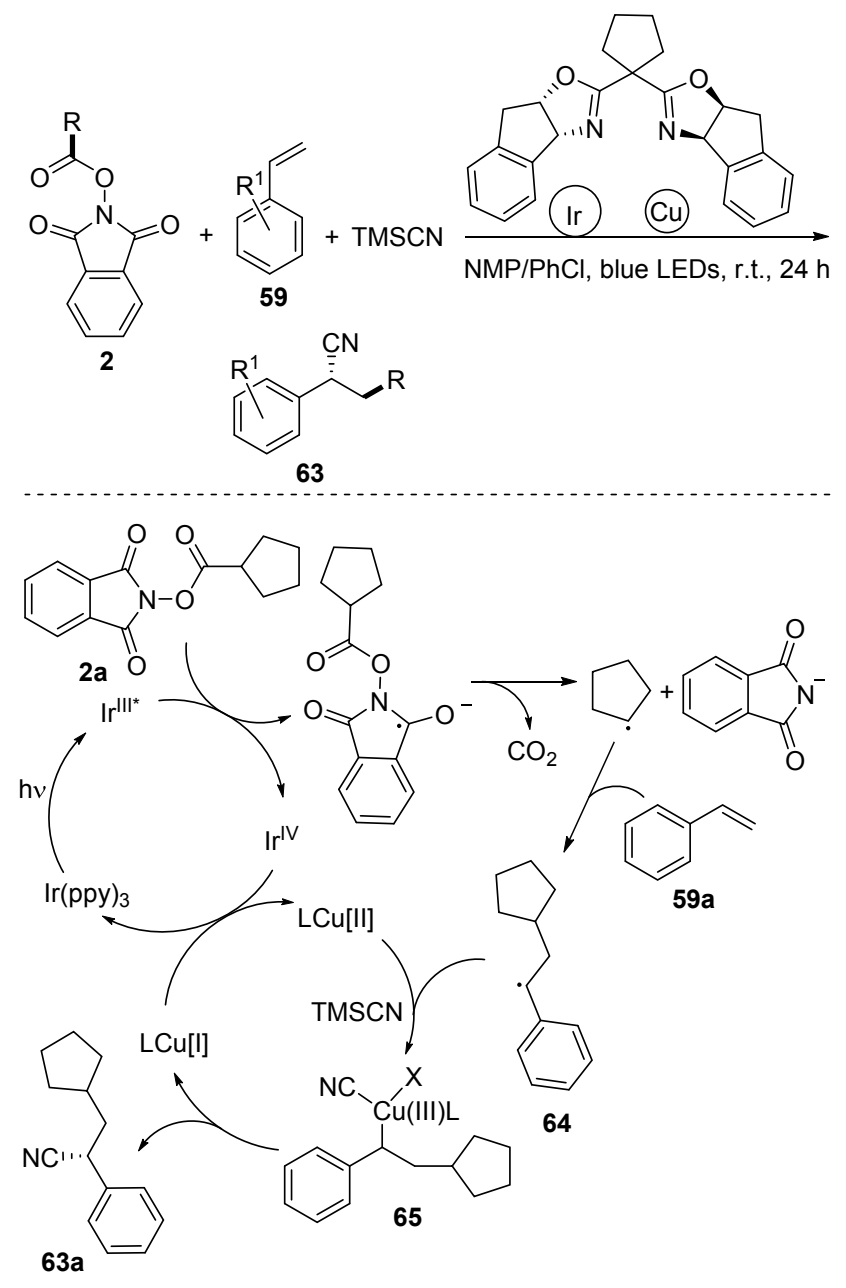

图式 11 苯乙烯的手性自由基氰烷基化反应

Scheme 11 Enantioselective radical cyanoalkylation of styrenes

\section{2 加成环化反应}

自由基串联环化反应在 “一锅反应” 中可以连续地 形成多个化学键, 已经成为有机合成中提高反应效率的 理想策略之一. Wang 等 ${ }^{[48]}$ 报道了可见光条件下有机染 料荧光素催化的 $N$-芳基甘氨酸与 $N$-苯基马来酰亚胺 $\mathbf{6 6}$ 的氨烷基化反应(Eq. 11), 在可见光氧化还原催化剂作
用下 $N$-芳基甘氨酸形成的 $\alpha$-氨甲基自由基与 $N$-苯基马 来酰亚胺的双键加成，随后经历环化/芳构化过程，以良 好的收率得到一系列类似天然化合物 67. 该氨甲基化 反应条件温和，分离产率良好，适应于各类亲电性和亲 核性的受体.

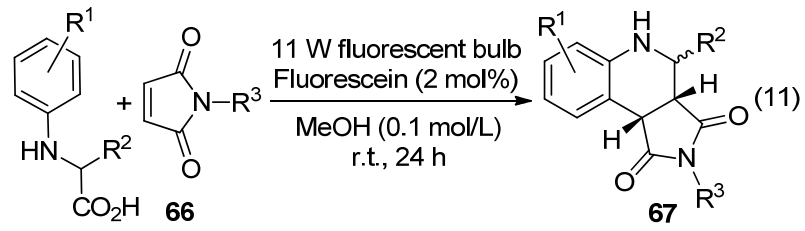

Aggarwal 课题组 ${ }^{[49]}$ 报道了可见光促进的脱羧自由 基加成-极性环化反应构建功能化环丙烷化合物 (Scheme 12), 作者认为烷基羧酸与缺电子烯烃 68 通过 还原过程的自由基极性反转得到碳负离子中间体，其与 烷基氯代物发生分子内的烷基化反应，得到环丙烷化合 物 69. 该反应体系表现出良好的官能团容忍性，适用于 各类烷基羧酸和卤代烷基烯烃化合物，提供了一条高原 子经济性的制备各类环丙烷化合物的合成路线.

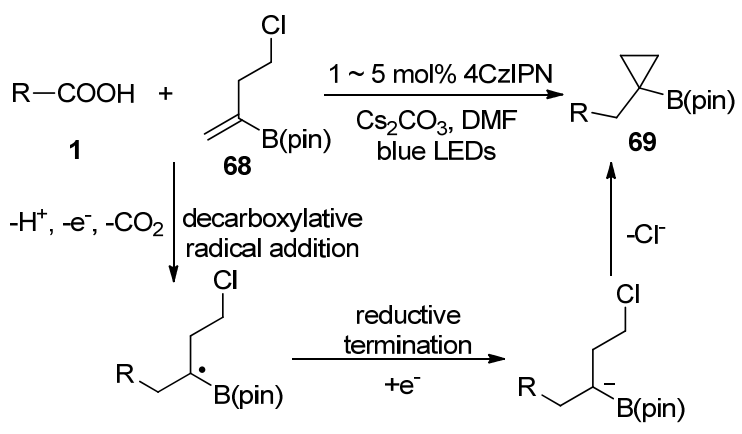

图式 12 功能化环丙烷化合物的合成

Scheme 12 Synthesis of functionalized cyclopropanes

脱羧自由基环化反应可以简单高效地构建各类杂 环化合物, Jamison 等 ${ }^{[50]}$ 开发了一种简单高效制备吡咯 并 [1,2- $\alpha$ 喹喔啉衍生物 72 及含有喹喔啉骨架或类似物 的方法. 反应过程中烷基羧酸与 $\mathrm{PhI}(\mathrm{OAc})_{2}$ 发生配体复 分解形成 $\mathrm{PhI}(\mathrm{OCOR})_{2}$, 其在可见光氧化还原体系形成 烷基自由基，随后发生自由基加成形成亚胺中间体自由 基 71. 孙培培等 ${ }^{[51]}$ 报道了烷基羧酸与芳基丙烯酰胺衍 生物 73 的脱羧烷基化串联腈基插入/环化反应. 烷基羧 酸在有机染料催化体系中难以发生脱羧自由基过程, 而 作者巧妙地将有机染料和过硫酸铵相结合，实现了烷基 羧酸的脱羧自由基，从而发生随后的腈基插入及环化等 过程，得到烷基菲定化合物 75，作者认为反应涉及亚胺 氮自由基中间体 74. 由于使用有机染料与过硫酸铵的 结合体系，避免了昂贵可见光金属催化剂的使用，提高 了反应的经济性. 
<smiles>Nc1ccccc1-n1cccc1</smiles>

(1) $\mathrm{Phl}(\mathrm{OAc})_{2}, \mathrm{RCOOH}$

(2) fac-Ir(ppy) ${ }_{3}(1 \mathrm{~mol} \%)$ $26 \mathrm{~W}$ fluorescent bulb DMF, $25^{\circ} \mathrm{C}$<smiles>[R]c1nc2ccccc2n2cccc12</smiles>

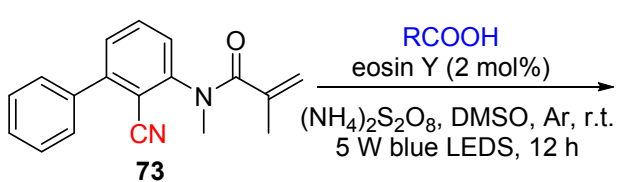<smiles>[R]C[C@@]1(C)C(=N)c2c(-c3ccccc3)cccc2N(C)C1=O</smiles><smiles></smiles>

iminyl radical

HAS: homolytic aromatic substitution

图式 13 脱羧烷基化串联环化反应

Scheme 13 Decarboxylative alkylation cascade cyclization

3,3-二烷基吲哚酮化合物吲哚酮广泛存在于天然产 物和具有生物学活性的药物分子之中, 朱成建课题 组 ${ }^{[52]}$ 采用可见光诱导的丙烯酰胺 76 与烷基羧酸的串联 自由基环化反应，构筑了一系列具有四级碳中心的吲哚 酮化合物 77 (Eq. 12), 该反应体系底物普适性良好, 适 应于各种一级、二级及三级烷基羧酸. 程辟课题组 ${ }^{[53]}$ 报 道了可见光条件下以 $N$-羟基邻苯二甲酰亚胺酯作为烷 基自由基前驱体的串联自由基环化反应，高效制备了 3,3-二烷基吲哚酮化合物 77 (Eq. 13), 该反应条件温和, 避免了具有易爆性的有机过氧化物类氧化剂的使用，但 是仅适用于三级烷基自由基，对于一级、二级烷基自由 基则不适用.
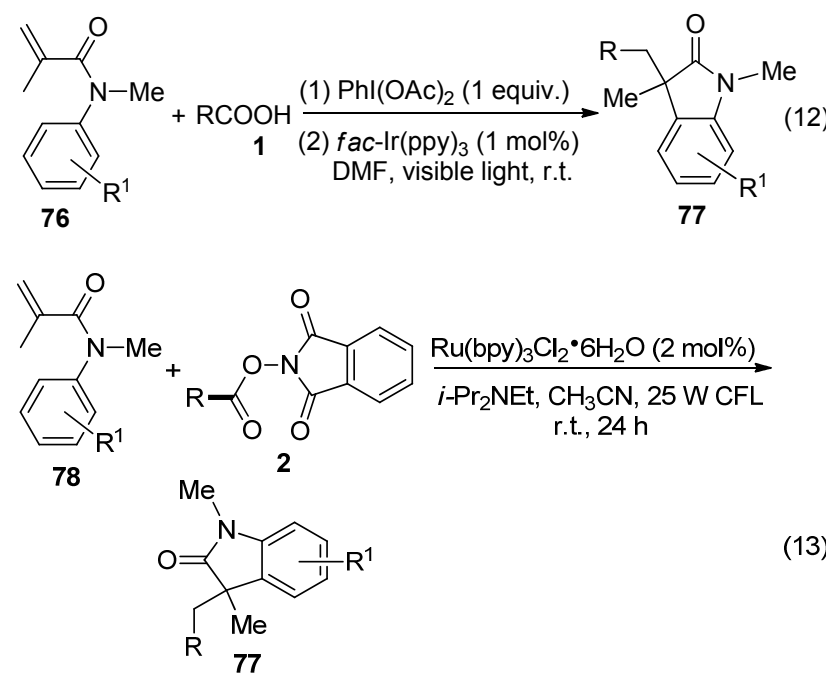

潘毅课题组 ${ }^{[54]}$ 研究了可见光促进的不饱和羧酸的 烷基化/内酯化反应，高效地合成了具有生物学活性的 烷基内酯化合物 80 (Eq. 14). $N$-差弪基邻苯二甲酰亚胺酯 经历脱䍨过程形成烷基自由基，随后与不饱和炔酸发生 自由基加成内酯化反应，反应体系中的质子酸和水均起 到重要的作用，提供了一条由不饱和羧酸出发简单高效 制备烷基取代内酯化合物的合成路线. 肖文精课题 组 ${ }^{[55]}$ 报道了可见光促进的环烷醇取代的苯乙烯与 $N$-差弪 基邻苯二甲酰亚胺酯经历烷基自由基加成与半频哪醇 重排反应，合成了一系列环酮化合物 82 (Eq. 15). Reiser 等 ${ }^{[56]}$ 利用同样方法合成一系列螺丁烯酸内酯化合物及 2,3-端环化呋喃化合物。
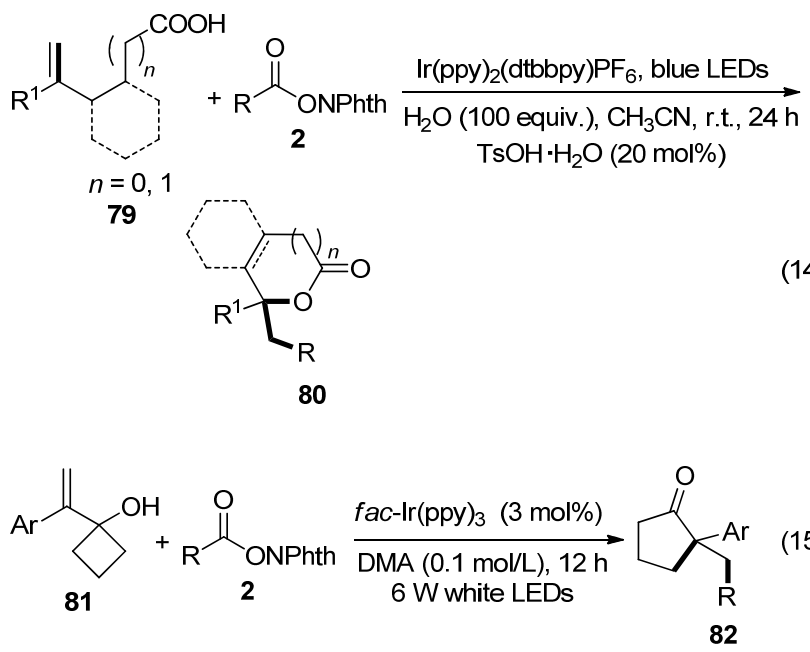

郭丽娜等 ${ }^{[57]}$ 以乙烯基叠氮化合物 83 与烷基 $N$-差基 邻苯二甲酰亚胺酯为原料，制备了一系列烷基取代的菲 啶化合物 84 (Eq. 16). 在可见光条件下 $N$-羟基邻苯二甲 酰亚胺酯脱羧形成烷基自由基，烷基自由基与乙烯基叠 氮的烯基加成脱氮形成氮自由基，随后发生环化得到目 标产物. 该串联自由基环化反应体系适用于一级、二级 和三级 $N$-羟基邻苯二甲酰亚胺酯，以中等到良好的收 率得到菲啶化合物，反应体系无需过渡金属催化剂和氧 化剂, 反应的经济性高.

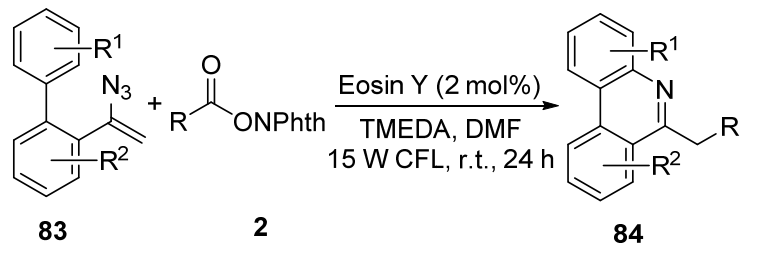

除了氮杂和氧杂环化合物, 有机磷杂环化合物在有 机化学中也具有重要作用. 周永波等 ${ }^{[58]}$ 报道了一种简 单高效地制备苯并 $[b]$ 磷杂环化物 86 的合成路线(Eq. 17). 在可见光作用下 $N$-羟基邻苯二甲酰亚胺酯与炔基 膦氧化物发生自由基加成及环化过程, 高效地构建了带 
有各种官能团的苯并 $[b]$ 磷杂环化物. 与传统方法相比, 该反应体系不需要使用任何金属催化剂, 因此无需考虑 因为膦配位能力而导致的过渡金属残留，同时反应无需 使用强氧化剂, 大大提高了底物的官能团容忍性.

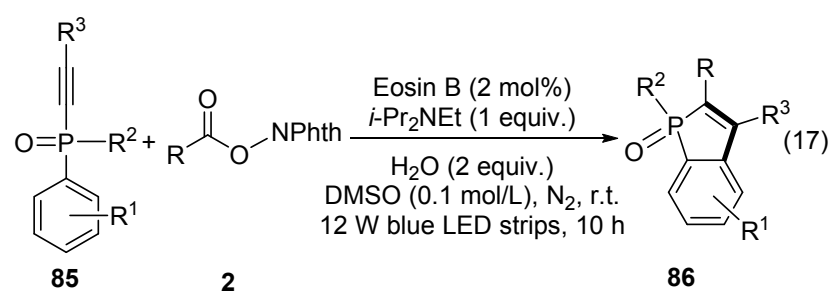

\section{3 芳杂环加成反应}

含氮杂环化合物广泛存在于天然产物、医药化学和 农药分子之中, 因此氮杂环化合物的直接碳氢键官能团 化反应一直受到广大科研工作者的关注. 其中 Minisci 型反应是非常经典的氮杂环官能团化反应, 近来可见光 氧化还原体系的 Minisci 型反应得到了快速发展. 2017 年, Glorius 课题组 ${ }^{[59]}$ 研究了可见光促进的芳杂环与烷基 羧酸的脱羧烷基化反应(Scheme 14). 反应可能历程如 下: 在蓝光照射下 $\operatorname{Ir}(\mathrm{III})$ 形成具有长寿命和强还原性的 激发态* $\operatorname{Ir}(\mathrm{III})$, 其还原过硫酸根负离子得到 $\operatorname{Ir}(\mathrm{IV})$ 和硫 酸负离子自由基, 环己羧酸与硫酸负离子自由基之间发 生氢原子转移得到环己基自由基, 环己基自由基与 4-甲 基喹啉加成得到中间体 89,89 随后经历去质子单电子氧 化得到目标化合物 88. 该反应体系具有良好地官能团 容忍性, 适用于(异)喹啉、吡啶、2,3-二氮杂荎及苯并噻 坐等杂环衍生物及氨基酸和各种脂肪酸化合物, 由于反 应的原料来源丰富, 该方法极大地便利了相关的各种具 有药学活性分子的快速合成. 由于可见光铱催化剂价格 相对昂贵，陆续有科研工作者开发了替代的方案. Ackermann 课题组 ${ }^{[60]}$ 将浐啶高氯酸盐与钴协同催化体 系结合, 实现了金刚烷羧酸与杂环的直接脱羧烷基化反 应, 使用钴催化剂能够再生吅啶高氯酸盐, 从而避免了 额外氧化剂的使用, 但作者仅仅研究了金刚烷羧酸作为 烷基自由基源. 不久, 李洋等 ${ }^{[6]]}$ 报道了钴/铱协同催化 的 Minisci 烷基化反应，反应中不需要大量碱，同时适用 于各种烷基羧酸. 王否课题组 ${ }^{[62]}$ 利用可见光催化剂浐 啶高氯酸盐与空气中的氧分子相结合, 也高效地实现了 杂环的直接烷基化反应. 张博等 ${ }^{[63]}$ 开发了无需额外可 见光催化剂和酸添加剂的反应体系, 在可见光作用下三 氟乙酸碘苯与烷基羧酸原位形成的高碘物种发生均裂 得到烷基自由基, 从而实现杂环的直接烷基化. 这些催 化体系的开发都极大地丰富了杂环化合物烷基化的合 成方法学.

基于可见光与 Brønsted 酸协同催化体系，傅尧课题

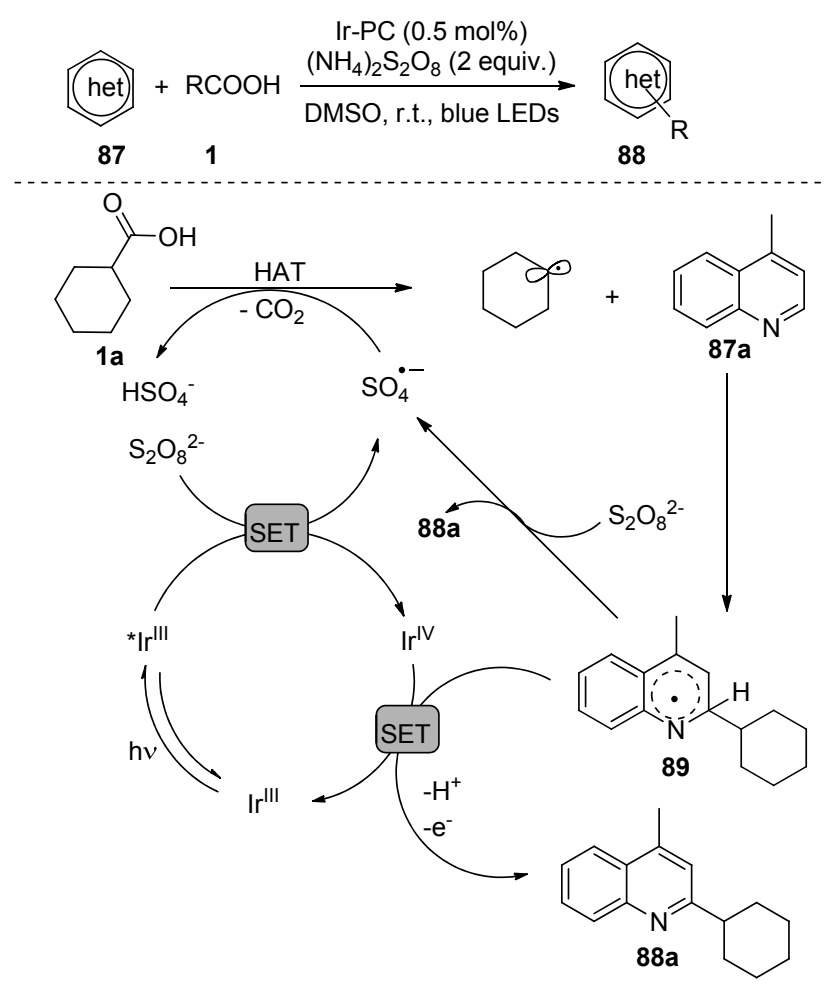

图式 14 芳杂环的脱羧碳氢烷基化反应

Scheme 14 Decarboxylative $\mathrm{C}-\mathrm{H}$ alkylation of heteroarenes

组 ${ }^{[64,65]}$ 报道了烷基 $N$-羟基邻苯二甲酰亚胺酯与芳杂环 的脱羧烷基化反应(Eq. 18)，其中可见光催化促进烷基 自由基的形成, Brønsted 酸增加杂环化合物的电子云密 度，实现了烷基自由基与芳杂环的交叉偶联. 反应具有 良好的底物普适性，适用于各类烷基羊酸酯、天然/非天 然氨基酸酯及二肽/三肽酯化合物，提供了一种简单高 效合成 $\alpha$-氨甲基及烷基取代的吡啶和喹啉等杂环化合 物的方法. 可见光催化自由基的不对称合成反应是光催 化领域具有挑战性课题之一, Phipps 课题组 ${ }^{[66]}$ 通过可见 光与手性 Brønsted 协同催化芳杂环的脱羧烷基化反应, 实现了手性 $\alpha$-氨甲基杂环化合物 $\mathbf{9 2}$ 的高效合成(Eq. 19). 反应机理与傅尧等报道的催化体系相一致 ${ }^{[64]}$, 作者认 为手性来源于手性磷酸与 $\alpha$-氨甲基自由基以及芳杂环 之间的强烈氢键作用. 该反应体系具有非常优秀的对映 选择性和官能团兼容性，从简单原料出发合成了一系列 具有高附加值的化合物，同时可用于各种药物分子的后 期功能化修饰. 江智勇等 ${ }^{[67]}$ 研究了非金属可见光催化 体系下 $\alpha$-氨甲基自由基与异喹啉加成合成手性 $\alpha$-氨甲 基异喹啉化合物 94 (Eq. 20). Sherwood 等 ${ }^{[68]}$ 报道了以 4-CzIPN 作可见光催化剂, 烷基羧酸为烷化试剂的 “一 锅两步” 的 Minisci 反应. Opatz 等 ${ }^{[69]}$ 研究了 $\mathrm{Ru}(\mathrm{bpy})_{3} \mathrm{Cl}_{2}$ 作可见光催化剂的类似反应体系.

2019 年, 傅尧课题组 ${ }^{[70]}$ 首次实现了以三苯基膦和 碘化钠复合体系作催化剂的芳杂环化合物的烷基化反 


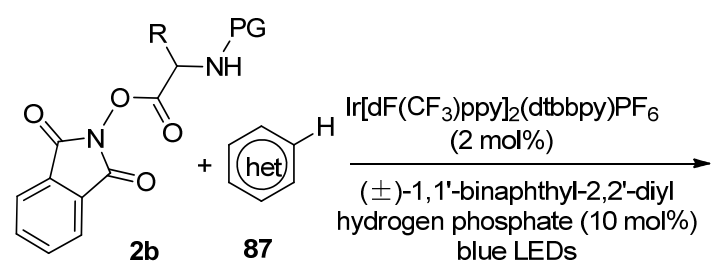<smiles>[R]C(NP)c1ccccc1</smiles>

90

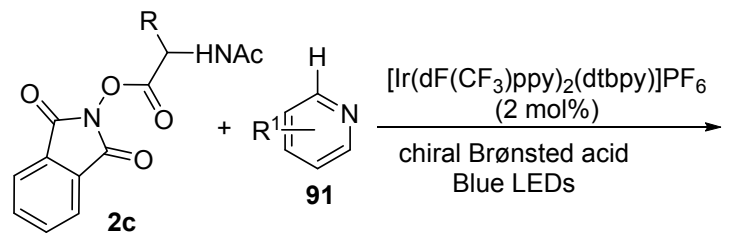<smiles>[R][R1]1ccc(C([R])N)n1</smiles><smiles>[R]CC(NC(=O)OCC)C(=O)ON1C(=O)c2ccccc2C1=O</smiles>

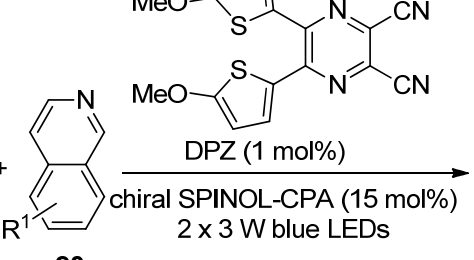

93

2d<smiles>[R]CC(NCC(=O)OC)c1nccc2c[R12](C=C)ccc12</smiles>

94

应(Scheme 15). 通常可见光催化剂与 $N$-羟基邻苯二甲 酰亚胺酯发生单电子转移形成烷基自由基, 而该复合体

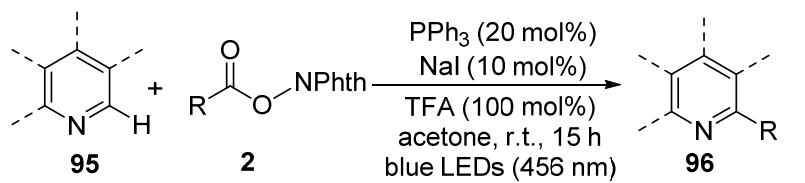

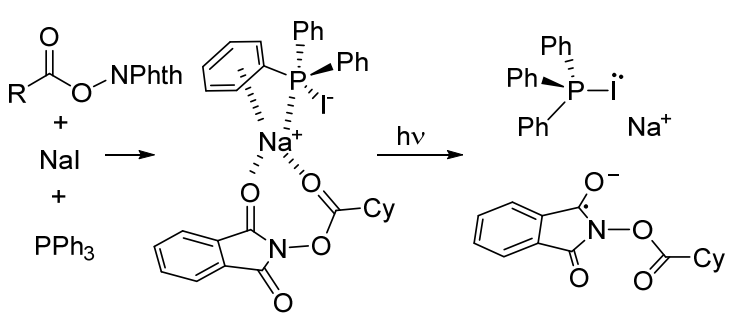

图式 15 三苯基膦/碘化钠介导的光催化脱羧烷基化反应 Scheme 15 Photocatalytic decarboxylative alkylations mediated by triphenylphosphine and sodium iodide
系是通过与 $N$-羟基邻苯二甲酰亚胺酯发生分子内电荷 转移得到烷基自由基物种. 这种复合催化体系首次成功 地将分子间电荷转移用于光氧化还原催化体系, 而且引 入手性磷酸催化剂后能够高效地实现对映立体选择性. 廉价三苯基膦和碘化钠的催化体系具有良好的官能团 兼容性及优秀的对映选择性, 将在有机合成及药物分子 开发等领域发挥重要的作用.

\section{4 自由基偶联反应}

自由基之间交叉偶联反应已经成为构建新型碳-碳 键强有力的手段之一，但是两种不同活性自由基之间的 选择性偶联依然面临挑战. 2014 年, MacMillan 课题组 ${ }^{[71]}$ 研究了可见光促进的 $\alpha$-氨基酸与苯腈的脱羧自由基偶 联反应，以良好的收率得到了一系列茮胺类化合物 98 (Scheme 16). 在可见光氧化还原催化剂的作用下 $\alpha$-氨 基酸脱羧得到烷基自由基，苯腈得到芳烃自由基负离 子，随后两种自由基之间发生交叉偶联及腈基消除得到 目标化合物. 该方法适用于各类 $\alpha$-氨基酸化合物, 能够 一步将生物质转化为药物分子.

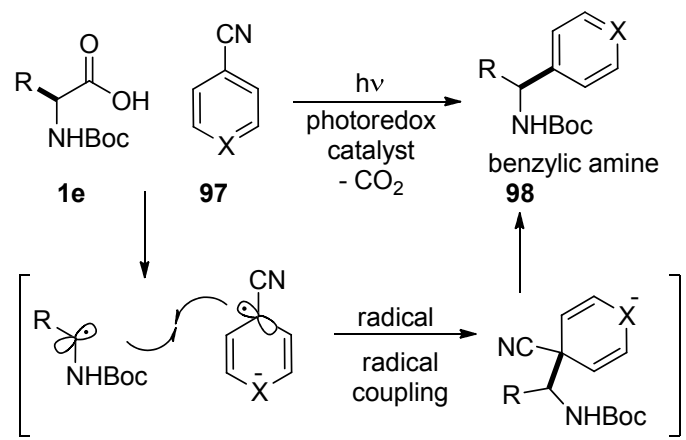

图式 16 可见光催化脱羧芳基化反应

Scheme 16 Decarboxylative arylation via photoredox catalysis

Tunge 等 ${ }^{[72]}$ 报道了可见光与钯协同催化体系中氨基 烷基羧酸(酯)的脱羧烯基化反应(Scheme 17), 在 $\operatorname{Pd}(0)$ 的作用下烯基酯化合物形成 $\mathrm{Pd}-\pi$ 烯丙基物种与羧酸盐 负离子 103 , 在可见光氧化还原体系下羧酸盐负离子 103 氧化后脱羧形成稳定的苄基自由基 104, 而烯丙基 钯物种被还原形成烯丙基自由基，随后发生自由基偶联 得到脱羧烯基化产物，若氨基烷基羧酸作底物，则反应 体系需要加入烯丙基甲基碳酸酯，从而原位形成羧酸 酯. 过渡金属与可见光协同催化体系拓宽了脱羧自由基 烷基化反应的应用范围.

单氟烯基化分子在医药、农药及材料等领域有非常 重要的应用. 2017 年, 付华课题组 ${ }^{[73]}$ 报道了可见光条件 下 $\alpha$-氨基酸与偕二氟烯烃化合物 105 的自由基偶联反 应，制备了单氟烯基化合物 106 (Eq. 21). $\alpha$-氨基酸是自 然界中最常见的具有生物学活性的有机分子, 在可见光 


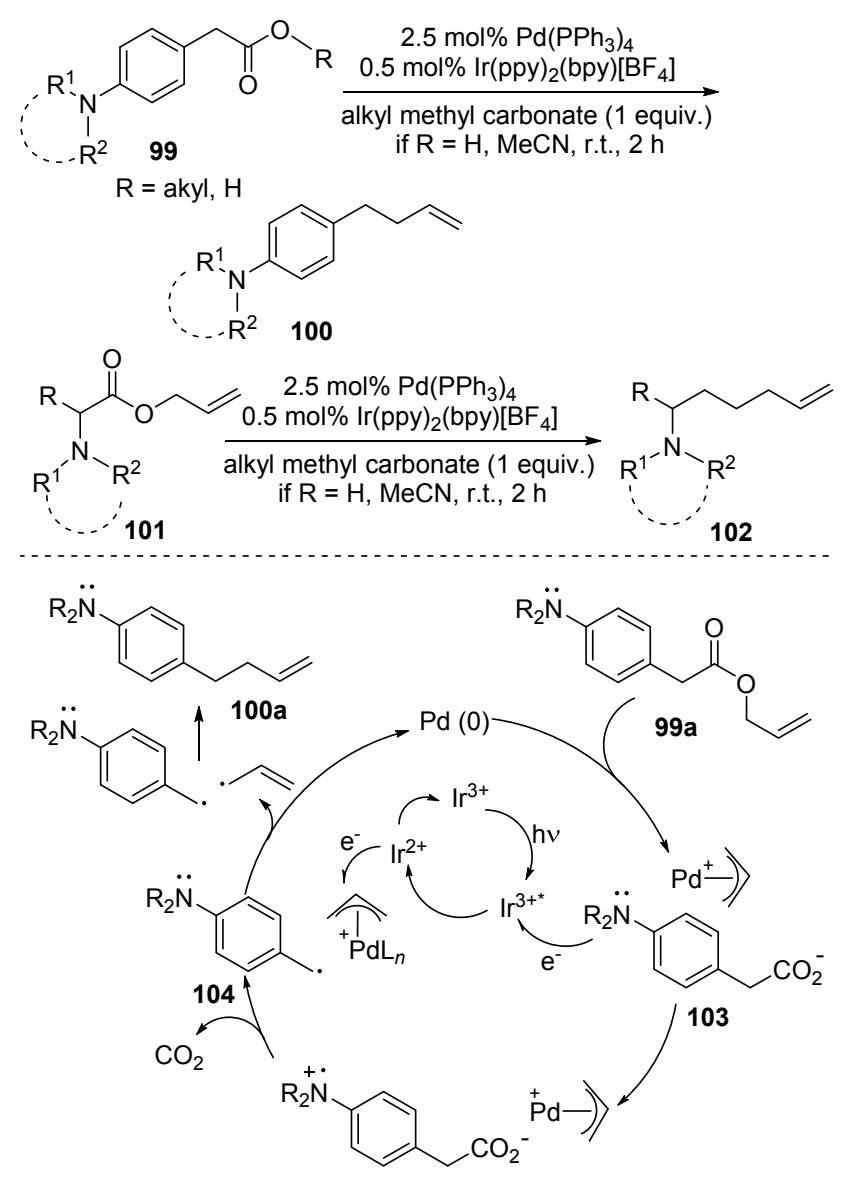

图式 17 可见光与钯协同催化脱羫烯基化反应

Scheme 17 Decarboxylative allylation via photoredox and palladium catalysis

氧化还原催化剂和碱的作用下， $\alpha$-氨基酸脱除二氧化碳 得到 $\alpha$-氨甲基自由基, 与此同时偕二氟烯烃分子得到一 个电子脱去氟负离子形成单氟烯基自由基, 两种自由基 高选择性地发生偶联生成 $\alpha$-氨基单氟烯基化合物，可见 光催化体系完成循环再生. 但当作者选用烷基羧酸作为 自由基前驱体时, 偶联反应收率很低. 最近, 安光辉等 [74]使用 4-CzIPN 作催化剂, 6 ewquiv.的碳酸铯作碱, 成 功地实现了烷基羧酸与偕二氟烯烃化合物的脱羧自由 基偶联. 该反应在太阳光作用下也能顺利进行，而且可 以高效地进行复杂分子的后期功能化.

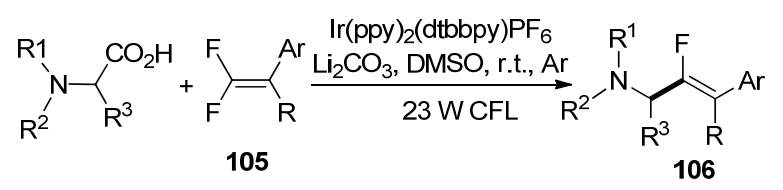

2018 年, 翁江等 ${ }^{[75]}$ 报道了可见光促进的亚胺 $\mathbf{1 0 7}$ 与 苯乙酸类化合物的脱羧苄基化反应(Scheme 18). 简单 的一级、二级和三级芳基乙酸作为理想的芐基自由基源, 在可见光氧化还原体系中苯乙酸被氧化得到苄基自由 基, 而相应的亚胺被还原成亚胺自由基负离子, 二者相
互结合得到目标偶联化合物. 该反应体系与之前报道的 亚胺苄基化反应相比，避免了底物预官能团化及 $\alpha$-位含 杂原子化合物的使用，提供了一条简单高效、操作方便且 条件温和的制备 $\beta$-芳基乙胺化合物 108 的合成路线.

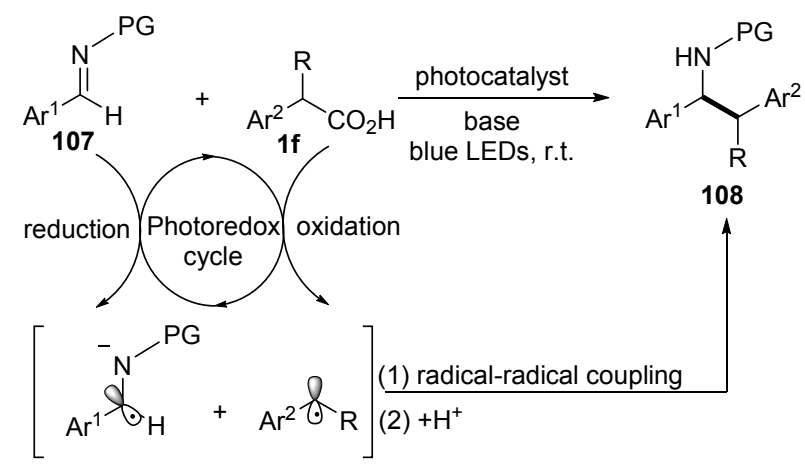

图式 18 可见光促进的脱羧苄基化反应

Scheme 18 Photocatalytic decarboxylative benzylation

2018 年，丛欢等 ${ }^{[76]}$ 报道了可见光条件下 $N$-芳基四 氢异喹啉 109 与 $N$-差欮基邻苯二甲酰亚胺酯的脱羧烷基 化反应(Eq. 22). 以有机染料敏化半导体材料作为可见 光催化剂, 它能够氧化 $N$-芳基四氢异喹啉去质子化得 到苄基自由基，还原 $N$-羟基邻苯二甲酰亚胺酯得到烷 基自由基，两种自由基之间快速结合得到烷基取代的四 氢异喹啉化合物 110. 这种廉价的有机敏化半导体材料 催化体系避免了贵重金属的使用，降低了反应的成本， 提高了反应的经济性.

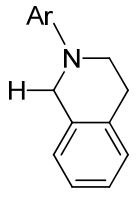

109

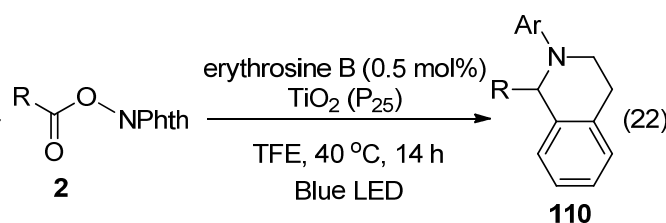

110
2018 年, 许兆青课题组 ${ }^{[77]}$ 报道了可见光促进的甘 氨酸和多肽酯化物的脱羧烷基化反应(Eq. 23). 作者开 发了一种新型的廉价铜与配体相结合的可见光催化体 系，该催化体系中铜配体络合物 $[\mathrm{Cu}(\mathrm{I}) \mathrm{L}]$ 能够吸收可见 光到达激发态 $[\mathrm{Cu}(\mathrm{I}) \mathrm{L}]^{*}$ ，还原 $N$-羟基邻苯二甲酰亚胺 酯形成烷基自由基和 $[\mathrm{Cu}(\mathrm{II}) \mathrm{L}]$, 而 $[\mathrm{Cu}(\mathrm{II}) \mathrm{L}]$ 氧化甘氨酸 衍生物得到自由基阳离子，随后在碱的作用下得到稳定 的 $\alpha$-氨甲基自由基，两种自由基交叉偶联得到目标产 物，铜催化剂还原再生. 该反应体系具有良好的底物普 适性，成功地实现了多种非天然氨基酸的制备和多肽化 合物的烷基化修饰.

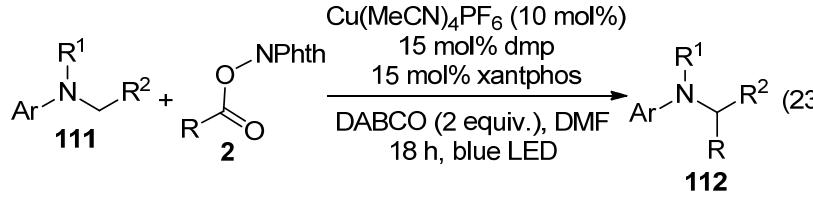




\section{M-R 交叉偶联反应}

在可见光氧化还原体系中, 烷基羧酸及衍生物是一 类理想的烷基自由基前驱体，而过渡金属催化体系中过 渡金属与卤代烃能够发生氧化加成得到 M-R 物种, 其 与自由基结合发生还原消除能够构建新的碳-碳键. 基 于此思路, 过渡金属与可见光协同催化卤代烃与烷基羧 酸的直接交叉偶联反应受到了广泛关注.

2014 年, MacMillan 课题组 ${ }^{[78]}$ 首次报道了过渡金属 镍和可见光协同催化的 $\alpha$-氨基羧酸与芳基卤化物 113 直 接交叉偶联构建新的 $\mathrm{C}\left(\mathrm{sp}^{3}\right)-\mathrm{C}\left(\mathrm{sp}^{2}\right)$ 键( Scheme 19). 反 应的可能历程如下: 在可见光照射下铱催化剂吸收能量 到达激发态, 在 $\operatorname{Ir}(\mathrm{III}) *$ 与碱作用下烷基羧酸被氧化脱羧 得到烷基自由基 115, 同时芳基卤代物在 $\mathrm{Ni}(0)$ 的作用下 氧化加成得到 $\mathrm{Ni}(\mathrm{II})$ 中间体, $\mathrm{Ni}(\mathrm{II})$ 物种迅速捕捉体系中 的自由基得到加合物 $\mathrm{Ni}(\mathrm{III})$, 最后经历还原消除得到目 标产物. 随后, 他们 ${ }^{[79]}$ 将芳基卤代物拓展到烷基溴代 物，在温和条件下通过简单丰富的烷基羧酸及烷基卤化 物的偶联反应构建 $\mathrm{C}\left(\mathrm{sp}^{3}\right)-\mathrm{C}\left(\mathrm{sp}^{3}\right)$ 键. MacMillan 与 $\mathrm{Fu}$ 课 题组 ${ }^{[80]}$ 合作开发了镍与可见光协同催化体系的非对称 合成，从自然普遍存在的氨基酸和芳基卤化物出发，制 备了一系列具有高对映选择性的茮胺化合物. Oderinde 等 ${ }^{[81}$ 研究了分子氧、溶剂及光源对协同催化体系的影 响. Zhang 等 ${ }^{[82]}$ 用 4-CzIPN 作可见光催化剂来替代昂贵 的钉和铱光催化剂. Scaiano 等 ${ }^{[83}$ 报道了 $\mathrm{TiO}_{2}$ 和二甲氧 基乙烷氯化镍非均相催化体系中烷基羧酸与芳基碘化 物的偶联反应. ElMarrouni 等 ${ }^{[84]}$ 利用该协同催化体系简 单快速地合成了非核苷类逆转录酶抑制剂候选药

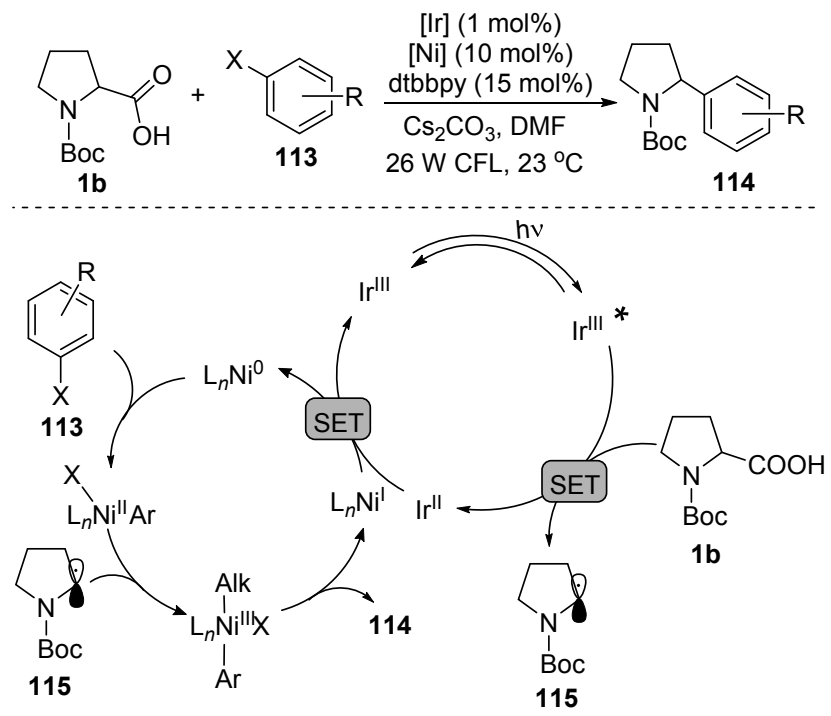

图式 19 可见光/镍协同催化脱羧偶联反应

Scheme 19 Photoredox-nickel catalyzed decarboxylative crosscoupling reaction doravirine 类似物.此类过渡金属镍与可见光氧化还原协 同催化体系很好地解决了传统合成方法中 $\mathrm{C}\left(\mathrm{sp}^{3}\right)$ $\mathrm{C}\left(\mathrm{sp}^{2}\right)$ 或 $\left(\mathrm{sp}^{3}\right)-\mathrm{C}\left(\mathrm{sp}^{3}\right)$ 键不易构建的问题.

基于铜与可见光协同催化体系, MacMillan 课题 组 ${ }^{[85]}$ 研究了烷基䍨酸与 Togni's 试剂 116 的脱羧三氟甲 基化反应(Eq. 24)，反应体系具有良好的官能团容忍性， 包括杂环、烯烃、醇及张力环，含有烷基羧酸的天然产 物及药物分子都可以利用该策略制备相应的三氟甲基 化产物，该方法能够实现复杂分子的后期三氟甲基官能 团化，在生物医药领域具有重要的应用前景. 付华课题 组 ${ }^{[86]}$ 报道了铜与可见光协同催化体系中 $\alpha$-氨基酸衍生 物与末端炔烃的脱羧烷基化反应(Eq. 25), 在简单温和 条件下以优秀至良好的收率制备了一系列丙炔胺化合 物 119. 研究表明, $\alpha$-氨基酸衍生物在可见光催化体系中 转化为 $\alpha$-氨甲基自由基， $\alpha$-甲基自由基继续被氧化成亚 胺阴离子, 与此同时末端炔与碘化铜形成炔铜物种, 随 后发生亲核进攻得到目标化合物.
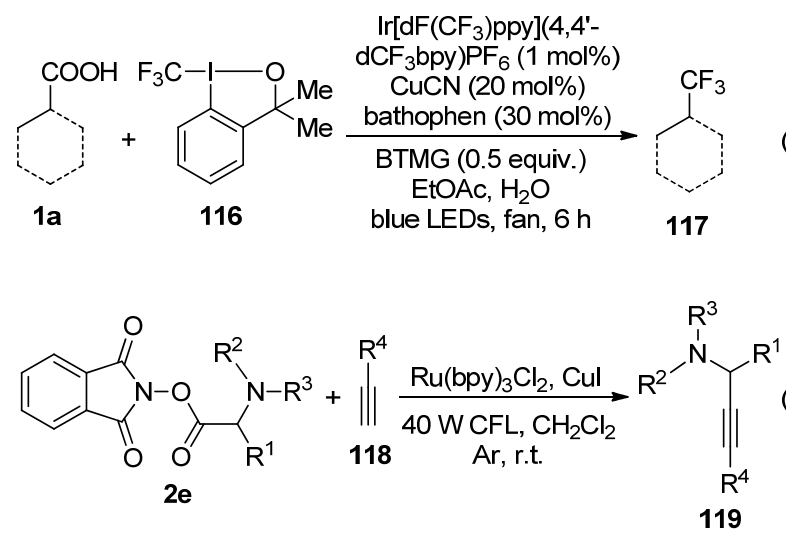

胡喜乐课题组 ${ }^{[87]}$ 利用铜与可见光协同催化体系, 实现了芳胺与 $N$-差基邻苯二甲酰亚胺酯的脱羧偶联反 应，制备了一系列烷基胺化合物，但是他们仅仅研究了 芳香胺类亲核试剂. 而 MacMillan 课题组 ${ }^{[88]}$ 报道了在铜 与可见光协同催化体系中烷基羧酸与各类胺化合物交 叉偶联构建碳一氮键 (Scheme 20). 反应的可能历程: $\mathrm{Cu}(\mathrm{I})$ 与亲核试剂胺 120 发生取代反应得到 $\mathrm{Nu}-\mathrm{Cu}(\mathrm{I})$ 物 种 122, $\mathrm{Ir}$ 光敏剂将 $\mathrm{Nu}-\mathrm{Cu}(\mathrm{I})$ 的电子转移给活化的羧酸 形成环己基自由基，与此同时 $\mathrm{Nu}-\mathrm{Cu}(\mathrm{II})$ 物种捕获环己 基自由基得到中间体 123, 其经过还原消除构建了碳一 氮键得到目标产物. 胡喜乐课题组 ${ }^{[87]}$ 的工作认为是 $\mathrm{Nu}-\mathrm{Cu}(\mathrm{I})$ 物种捕获烷基自由基形成 $\mathrm{Nu}-\mathrm{Cu}(\mathrm{II})-\mathrm{R}$ 中 间体. 该反应具有非常好的普适性，各种氮杂环胺、芳 香胺、酰胺等胺试剂与各种一级、二级与三级烷基羧酸 都能够顺利发生偶联反应，重要的是该反应体系能够用 于天然产物和药物分子的后期官能化. 


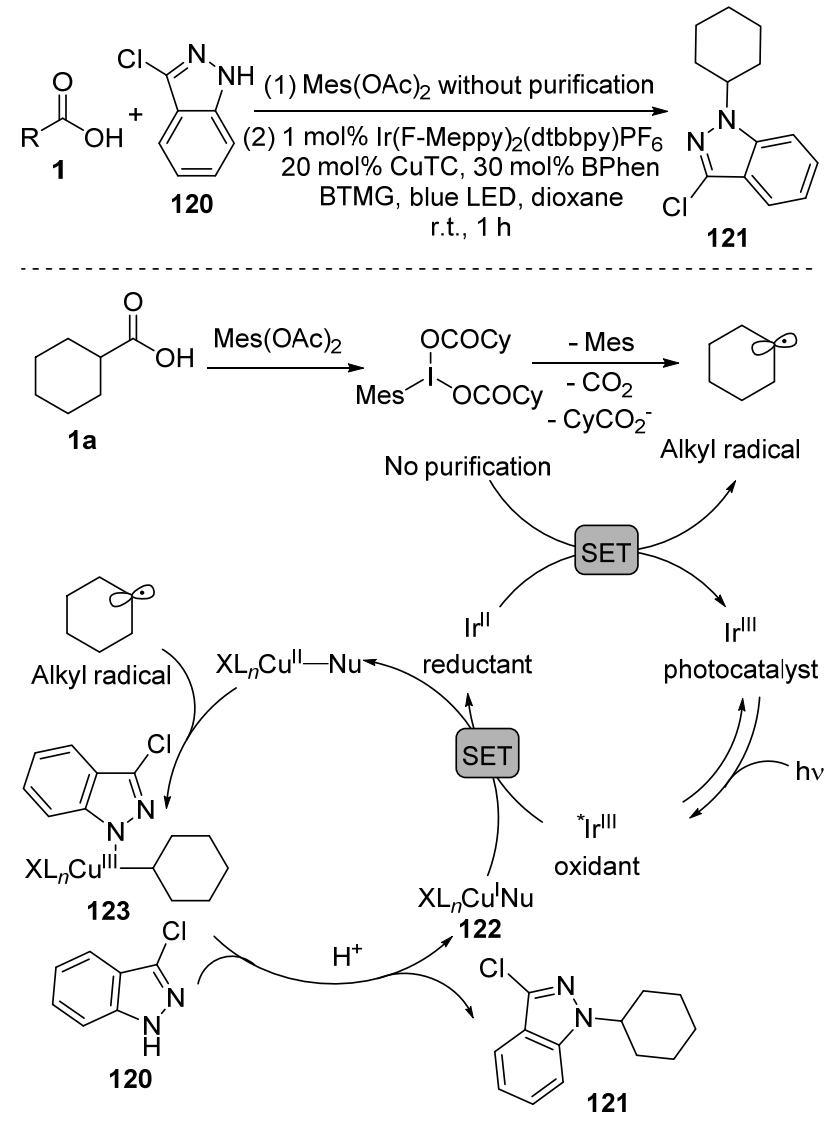

图式 20 脱羧碳一氮偶联反应

Scheme 20 Decarboxylative $\mathrm{C}-\mathrm{N}$ coupling reaction

\section{6 其它反应}

含氟有机化合物在医药、农药及材料等领域具有广 泛的应用, 在有机分子中引入氟原子能够显著改变其本 身的物理性质、化学性质和生物活性. 在可见光条件下 烷基羧酸的氟化反应也受到了越来越多的关注, Sammis 等 ${ }^{[89]}$ 首次实现了以 $\mathrm{Ru}(\mathrm{bpy})_{3} \mathrm{Cl}_{2}$ 作可见光催化剂, 选择 性氟试剂作氟源的苯氧乙酸的脱羧氟化反应(Eq. 26). 瞬态吸收光谱表明, $\mathrm{Ru}(\mathrm{II})$ 催化剂与选择性氟试剂之间 的单电子转移过程是反应体系的关键步骤. 此反应体系 相较之前的紫外光作用下的脱羧氟化反应具有重要的 突破，但仅仅苯氧乙酸适用该体系限制了其应用范围. 随后, MacMillan 及合作者 ${ }^{[90]}$ 研究了 $\left[\mathrm{Ru}(\mathrm{bpz})_{3}\right]\left(\mathrm{PF}_{6}\right)_{2}$ 或 $\left[\operatorname{Ir}\left\{\mathrm{dF}\left(\mathrm{CF}_{3}\right) \mathrm{ppy}_{2}(\mathrm{dtbbpy})\right] \mathrm{PF}_{6}\right.$ 作为光催化剂, 能够适用 于各种烷基羧酸的脱羧氟化反应(Eq. 27, condition A). 而叶金星等 ${ }^{[91]}$ 报道了有机染料催化的一级、二级和三级 烷基羧酸与选择性氟的脱羧氟化反应(Eq. 27, condition B), 制备了一系列具有高附加值的有机氟化合物 126. 由此可见, 可见光促进的脱羧自由基氟化反应能够高效 地将来源广泛的烷基羧酸转化为一系列烷基氟化物, 这 进一步丰富了有机氟化合物的合成方法学.

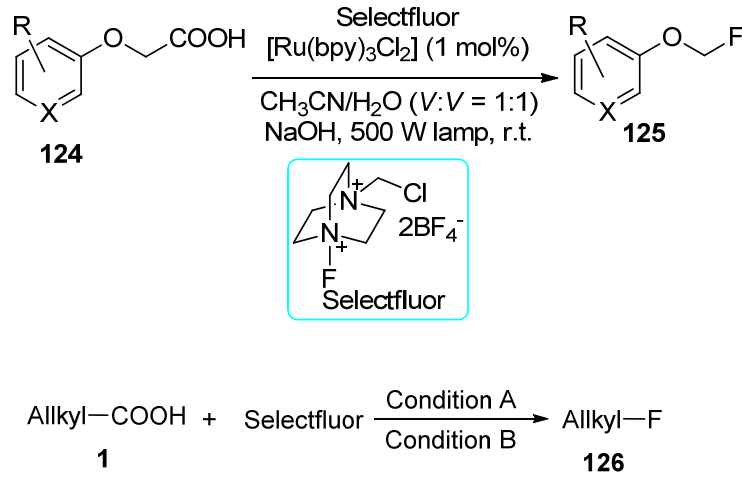

Condtion $\mathrm{A}:\left[\mathrm{Ru}(\mathrm{bpz})_{3}\right]\left(\mathrm{PF}_{6}\right)_{2}(1 \mathrm{~mol} \%)$ or $\left[\operatorname{lr}\left\{\mathrm{dF}\left(\mathrm{CF}_{3}\right) \mathrm{ppy}\right\}_{2}(\mathrm{dtbbpy})\right] \mathrm{PF} \mathrm{F}_{6}$ $\mathrm{CH}_{3} \mathrm{CN} / \mathrm{H}_{2} \mathrm{O}(\mathrm{V}: \mathrm{V}=1: 1), \mathrm{Na}_{2} \mathrm{HPO}_{4}, 34 \mathrm{~W}$ blue LED, $23^{\circ} \mathrm{C}$ Condition B: Mes-AcrClO $\mathrm{Cr}_{4}$ or Riboflavin (5 mol\%), $\mathrm{CH}_{3} \mathrm{CN} / \mathrm{H}_{2} \mathrm{O}(\mathrm{V}: \mathrm{V}=$ 1:1), $\mathrm{Cs}_{2} \mathrm{CO}_{3}, 23$ W CFL, r.t., $\mathrm{N}_{2}$

烷基胺化合物是一类重要的有机含氮化合物，通过 可见光促进的烷基羧酸与碳氮双键或氮氮双键的自由 基加成反应能够高效构建烷基胺化合物, Tunge 等 ${ }^{[92]}$ 报 道了可见光条件下烷基羧酸与偶氮二甲酸二异丙酯 $\mathbf{1 2 7}$ 的脱羧自由基加成反应，制备了一系列烷基胺化合物 128 (Eq. 28), 而烷基胺化合物在碱性条件下发生氮一氮 键断裂能够得到氨基甲酸酯化合物. Leonori 等 ${ }^{[93]}$ 则报 道了温和条件下烷基羧酸与亚硝基芳烃 129 的直接脱羧 自由基加成反应，合成了一系列烷基芳基羟胺化合物 130 (Eq. 29), 该反应体系被成功地应用于各种复杂烷基 酸的功能化修饰.
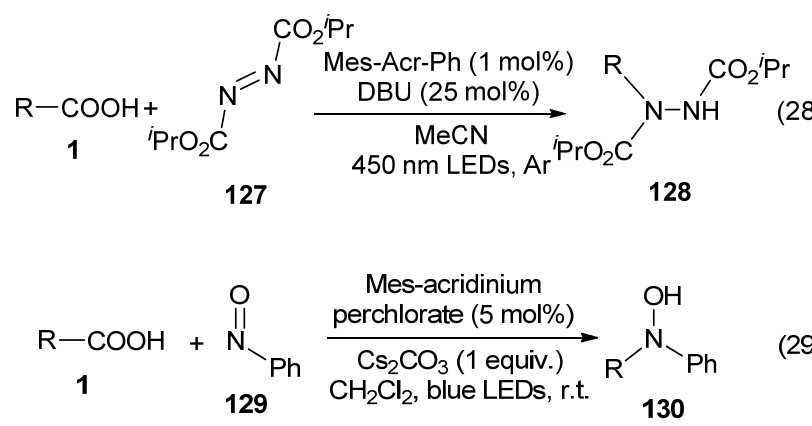

烷基嗍化合物是有机合成中一类非常重要的有机 合成子，李鹏飞课题组 ${ }^{[94]}$ 报道了一种在可见光条件下 简单高效合成烷基硼酸酯的方法, 以 $N$-羊筇基邻苯二甲 酰亚胺酯与硼酸酯/硼酸为起始原料, $\left[\operatorname{Ir}(\mathrm{ppy})_{2}-\right.$ (dtbpy)]PF 6 作光催化剂, 在可见光作用下能够高效地生 成三氟硣酸盐 131 及一级、二级烷基硼酸酯 132 (Scheme 21). 随后, Aggarwal 课题组 ${ }^{[95]}$ 报道了温和条件下无需使 用额外可见光催化剂，烷基 $N$-差基邻苯二甲酰亚胺酯 与双联邻苯二酚路酸酯的脱着硼化反应，经过频哪醇和 三乙胺的简单后处理得到稳定的频哪醇硼酸酯 132 (Scheme 21). 通常烷基 $N$-差基邻苯二甲酰亚胺酯需要 在可见光氧化还原催化剂作用下形成烷基自由基，作者 
通过自由基钟和相关控制实验, 认为在该反应体系中 $N$-着基邻苯二甲酰亚胺酯、双联邻苯二酚硼酸酯及 $N, N$ 二甲基乙酰胺(DMAc)溶剂形成了三元杂化络合物, 这 种络合物在可见光条件下通过分子内的电子转移直接 形成烷基自由基，从而完成脱羧硼化反应.

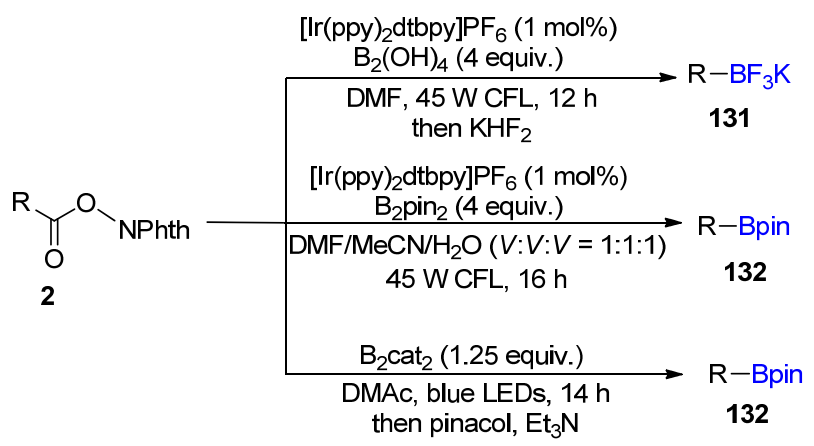

图式 21 可见光诱导的脱羧硼化反应

Scheme 21 Photoinduced decarboxylative borylation

付华课题组 ${ }^{[96]}$ 研究了在可见光条件下 $N$-羟基邻苯 二甲酰亚胺酯与二硒化合物 133 的脱羧偶联反应(Eq. $30)$, 在温和条件下以蛋白氨基酸、 $L$-天冬氨酸及谷氨酸 的衍生物 $N$-差基邻苯二甲酰亚胺酯作烷基自由基源以 及手性源, 高效地制备了一系列手性 $\alpha$-硒氨基酸衍生物 134, 利用该方法将有效地开发出更多具有生物和医药 活性的非天然手性 $\alpha$-氨基酸分子. 基于以上思路, 他 们 ${ }^{[97]}$ 报道了 $N$-羟基邻苯二甲酰亚胺酯与芳基硫酚 135 的脱羧偶联反应(Eq. 31), 作者认为 $N$-着基邻苯二甲酰 亚胺酯与碳酸铯能够结合形成在可见光范围内有吸收 的络合物, 而这种络合物充当反应体系的光敏剂, 从而 不需要额外的光催化剂.

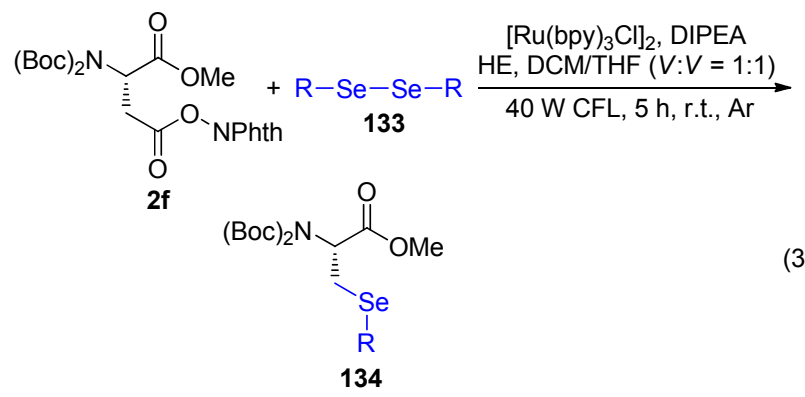<smiles></smiles>

\section{7 结论与展望}

综述了可见光促进的烷基羧酸及其衍生物脱羧偶 联反应的研究进展, 对脱羧自由基反应类型进行了归纳
和总结. 可见光促进的脱羧偶联反应已经被应用于各类 碳一碳及碳-杂键的高效构建, 实现了许多传统方法难以 完成的反应过程. 由于此类反应通过可见光提供能源且 一般是在室温条件下进行, 使得反应更绿色环保, 在有 机合成化学中具有重要应用.

尽管可见光促进的烷基羧酸及其衍生物的脱羧烷 基化偶联反应取得了快速的发展，该领域仍然存在诸多 挑战. 例如: 提高脱羧偶联反应中烷基自由基物种的化 学选择性和反应活性，实现烷基自由基中间体的精准高 效转化，有效调控自由基烷基化反应的立体选择性，开 发新型可见光催化体系及深入系统地研究反应机理. 此 外，可见光促进的脱羧烷基化反应在连续流动化学的发 展能够加快药物开发. 相信随着自由基化学的蓬勃发展 及广大科研工作者的不断努力, 可见光促进的自由基烷 基化反应将会得到长远的发展和应用.

\section{References}

[1] Lunbderg, H.; Tinnis, F.; Selander, N.; Adolfsson, H. Chem. Soc. Rev. 2014, 43, 2714.

[2] Morrill, L. C.; Smith, A. D. Chem. Soc. Rev. 2014, 43, 6214.

[3] Straathof, A. J. J. Chem. Rev. 2014, 114, 1871.

[4] (a) Sivaguru, P.; Wang, Z.; Zanoni, G.; Bi, X. Chem. Soc. Rev. 2019, 48, 2615.

(b) Wang, F.; Chen, P.; Liu, G. S. Acc. Chem. Res. 2018, 51, 2036.

(c) Yi, H.; Zhang, G.; Wang, H.; Huang, Z.; Wang, J.; Singh, A.; Lei, A. Chem. Rev. 2017, 117, 9016.

(d) Zhao, Y.; Liu, Z. Chin. J. Chem. 2018, 36, 455.

(e) Tan, F.; Yin, G. Chin. J. Chem. 2018, 36, 545.

(f) Cao, Y.; He, X.; Wang, N.; Li, H.; He, L.-N. Chin. J. Chem. 2018, 36, 644 .

[5] (a) Wang, H.; Wu, P.; Zhao, X.; Zeng, J.; Wan, Q. Acta Chim. Sinica 2019, 77, 231 (in Chinese).

(王浩, 吴品儒, 赵祥, 曾静, 万谦, 化学学报, 2019, 77, 231.)

(b) Chen, Y.; Chang, L.; Zuo, Z. Acta Chim. Sinica 2019, 77, 794 (in Chinese).

(陈奕霖, 常亮, 左智伟, 化学学报, 2019, 77, 794.)

(c) Ye, S.; Wu, J. Acta Chim. Sinica 2019, 77, 814 (in Chinese).

(叶盛青, 吴款, 化学学报, 2019, 77, 814.)

(d) Zhang, H.-H.; Yu, S. Acta Chim. Sinica 2019, 77, 832 (in Chinese).

(张洪浩, 俞寿云, 化学学报, 2019, 77, 832.)

(e) Ren, L.; Ran, M.; He, J.; Qian, Y.; Yao, Q. Chin. J. Org. Chem. 2019, 39, 1583 (in Chinese)

(任林静，由茂刚，何佳芯，钱燕，姚秋丽，有机化学，2019，39， 1583.)

[6] (a) Zhao, B.; Tan, H.; Chen, C.; Jiao, N.; Shi, Z. Chin. J. Chem. 2018, 36, 995.

(b) Yuan, Y.; Dong, W.; Gao, X.; Xie, X.; Curran, D.; Zhang, Z. Chin. J. Chem. 2018, 36, 1035.

(c) Li, C.; Qi, Z.; Yang, Q.; Qiang, X.-Y.; Yang, S.-D. Chin. J. Chem. 2018, 36, 1052.

(d) An, X.; Zhang, H.; Xu, Q.; Yu, L.; Yu, S. Chin. J. Chem. 2018, $36,1147$.

(e) Xu, W.; Dai, X.; Xu, H.; Weng, J. Chin. J. Org. Chem. 2018, 38, 2807 (in Chinese).

(徐雯秀, 戴小强, 徐涵靖, 翁建全, 有机化学, 2018, 38, 2807.)

(f) Ruan, L; Chen, C.; Zhang, X.; Sun, J. Chin. J. Org. Chem. 2018, 38, 3155 (in Chinese).

(阮利衡, 陈春欣, 张晓欣, 孙京, 有机化学, 2018, 38, 3155.)

[7] Sun, A.; C.; McAtee, R. C.; McClain, E. J.; Stephenson, C. R. J. 
Synthesis 2019, 51, 1063.

[8] Murarka, S. Adv. Synth. Catal. 2018, 360, 1735.

[9] Xuan, J.; Zhang, Z. G.; Xiao, W. J. Angew. Chem., Int. Ed. 2015, 54, 15632.

[10] Chu, L.; Ohta, C.; Zuo, Z.; MacMillan, D. W. C. J. Am. Chem. Soc. 2014, 136, 10886

[11] Miyake, Y.; Nakajima, K.; Nishibayashi, Y. Chem. Commun. 2013, 49, 7854.

[12] Millet, A.; Lefebvre, Q.; Rueping, M. Chem.-Eur. J. 2016, 22, 13464.

[13] Ramirez, N.; Gonzalez-Gomez, J. Eur. J. Org. Chem. 2017, 2154.

[14] Chinzei, T.; Miyazawa, K.; Yasu, Y.; Koike, T.; Akita, M. RSC Adv. 2015, 5, 21297.

[15] Bloom, S.; Liu, C.; Kölmel, D.; Qiao, J.; Zhang, Y.; Poss, M.; Ewing, W.; MacMillan, D. W. C. Nat. Chem. 2018, 10, 205.

[16] Kölmel, D. K.; Loach, R. P.; Knauber, T.; Flanagan, M. E. ChemMedChem 2018, 13, 2159.

[17] Chen, J.-Q.; Chang, R.; Wei, Y.-L.; Mo, J.-N.; Wang, Z.-Y.; Xu, P.-F. J. Org. Chem. 2018, 83, 253.

[18] Xiao, T.; Li, L.; Zhou, L. J. Org. Chem. 2016, 81, 7908.

[19] Noble, A.; Mega, R. S.; Pflästerer, D.; Myers, E.; Aggarwal, V. K. Angew. Chem., Int. Ed. 2018, 57, 2155.

[20] Guo, T.; Zhang, Y.; Fang, Y.; Jin, X.; Li, Y.; Li, R.; Li, X.; Cen, W.; Liu, X.; Tian, Z. Adv. Synth. Catal. 2018, 360, 1352.

[21] Yin, Y.; Dai, Y.; Jia, H.; Li, J.; Bu, L.; Qiao, B.; Zhao, X.; Jiang, Z. J. Am. Chem. Soc. 2018, 140, 6083 .

[22] Okada, K.; Okamoto, K.; Morita, N.; Okubo, K.; Oda, M. J. Am. Chem. Soc. 1991, 113, 9401

[23] Schnermann, N.; Overman, L. E. Angew. Chem., Int. Ed. 2012, 51, 9576.

[24] Pratsch,G.; Lackner, G. L.; Overman, L. E. J. Org. Chem. 2015, 80, 6025

[25] Hu, C.; Chen, Y. Org. Chem. Front. 2015, 2, 1352.

[26] Schwarz, J.; König, B. Green Chem. 2016, 18, 4743.

[27] Jin, Y.; Yang, H.; Fu, H. Org. Lett. 2016, 18, 6400.

[28] Noble, A.; MacMillan, D. W. C. J. Am. Chem. Soc. 2014, 136, 11602.

[29] Cao, H.; Jiang, H.; Feng, H.; Kwan, J.; Liu, X.; Wu, J. J. Am. Chem. Soc. 2018, 140, 16360.

[30] Zheng, C.; Chen, W.; Li, H.; Na, R.; Shang, R. Org. Lett. 2018, 20, 2559.

[31] Till, N. A.; Smith, R. T.; MacMillan, D. W. C. J. Am. Chem. Soc. 2018, 140, 5701 .

[32] Zhang, J.; Yang, J.; Guo, L.; Duan, X. Chem.-Eur. J. 2017, 23, 10259.

[33] Xu, K.; Tan, Z.; Zhang, H.; Liu, J.; Zhang, S.; Wang, Z. Chem. Commun. 2017, 53, 10719.

[34] Wang, G.; Shang, R.; Fu, Y. Org. Lett. 2018, $20,888$.

[35] Koy, M.; Sandfort, F.; Tlahuext-Aca, A.; Quach, L.; Daniliuc, C.; Glorius, F. Chem.-Eur. J. 2018, 24, 4552.

[36] Jin, C.; Yan, Z.; Sun, B.; Yang, J. Org. Lett. 2019, 21, 2064.

[37] Dai, G.; Lai, S.; Luo, Z.; Tang, Z. Org. Lett. 2019, 21, 2269.

[38] Li, Y.; Ge, L.; Qian, B.; Babu, K. R.; Bao, H. Tetrahedron Lett. 2016, 57, 5677 .

[39] Zhou, Q.; Guo, W.; Ding, W.; Wu, X.; Chen, X.; Lu, L.; Xiao, W. Angew. Chem., Int. Ed. 2015, 54, 11196.

[40] Yang, J.; Zhang, J.; Qi, L.; Hu, C.; Chen, Y. Chem. Commun. 2015, 51,5275 .

[41] Tlahuext-Aca, A.; Garza-Sanchez, R.; Glorius, F. Angew. Chem., Int. Ed. 2017, 56, 3708

[42] Ge, L.; Li, Y.; Jian, W.; Bao, H. Chem.-Eur. J. 2017, 23, 11767

[43] Quyang, X.; Li, Y.; Song, R.; Li, J. Org. Lett. 2018, 20, 6659.

[44] Tlahuext-Aca, A.; Garza-Sanchez, A.; Schäfer, M.; Glorius, F. Org. Lett. 2018, 20, 1546.

[45] Xia, Z.; Zhang, C.; Gao, Z.; Ye, S. Org. Lett. 2018, 20, 3496.

[46] Kong, W.; Yu, C.; An, H.; Song, Q. Org. Lett. 2018, 20, 349.

[47] Sha, W.; Deng, L.; Ni, S.; Mei, H.; Han, J.; Pan, Y. ACS Catal. 2018, 8, 7489 .
[48] Chen, L.; Chao, C.; Pan, Y.; Dong, S.; Teo, Y.; Wang, J.; Tan, C. Org. Biomol. Chem. 2013, 11, 5922.

[49] Shu, C.; Mega, R. S.; Andreassen, B. J.; Noblem A.; Aggarwal, V. K. Angew. Chem., Int. Ed. 2018, 57, 15430.

[50] He, Z.; Bae, M.; Wu, J.; Jamison, T. F. Angew. Chem., Int. Ed. 2014, 53, 14451 .

[51] Yu, Y.; Yuan, W.; Huang, H.; Cai, Z.; Liu, P.; Sun, P. J. Org. Chem. 2018, 83, 1654.

[52] Xie, J.; Xu, P.; Li, H.; Xue, Q.; Jin, H.; Cheng, Y.; Zhu, C. Chem. Commun. 2013, 49, 5672.

[53] Tang, Q.; Liu, X.; Liu, S.; Xie, H.; Liu, W.; Zeng, J.; Cheng, P. RSC Adv. 2015, 5, 89009

[54] Sha, W.; Ni, S.; Han, J.; Pan, Y. Org. Lett. 2017, 19, 5900

[55] Yao, S.; Zhang, K.; Zhou, Q.; Zhao, Y.; Shi, D.; Xiao, W. Chem. Commun. 2018, 54, 8096.

[56] Kachkovskyi, G.; Faderl, C.; Reiser, O. Adv. Synth. Catal. 2013, $355,2240$.

[57] Yang, J.; Zhang, J.; Zhang, J.; Duan, X.; Gao, L. J. Org. Chem. 2018, 83, 1598.

[58] Liu, L.; Dong, J.; Yan, Y.; Yin, S.; Han, L.; Zhou, Y. Chem. Commun. 2019, 55, 233.

[59] Garza-Sanchez, A.; Tlahuext-Aca, A.; Glorius, F. ACS Catal. 2017, $56,12336$.

[60] Koeller, J.; Gandeepan, P.; Ackermann, L. Synthesis 2019, 51, 1284.

[61] Tian, W.-F.; Hu, C.-H.; He, K.-N.; He, X.-Y.; Li, Y. Org. Lett. 2019 21, 6930 .

[62] Wang, B.; Li, P.; Miao, T.; Zou, L.; Wang, L. Org. Biomol. Chem. 2019, 17, 115

[63] Zhang, X.-Y.; Weng, W.-Z.; Liang, H.; Yang, H.; Zhang, B. Org. Lett. 2018, 20, 4686.

[64] Chen, W.; Shang, R.; Fu, Y. ACS Catal. 2017, 7, 907.

[65] Cheng, W.-M.; Shang, R.; Fu, M.-C.; Fu, Y. Chem.-Eur. J. 2017, 23, 2537.

[66] Proctor, R. S. J.; Davis, H. J.; Phipps, R. J. Science 2018, 360, 419.

[67] Liu, X.; Liu, Y.; Chai, G.; Qiao, B.; Zhao, X.; Jiang, Z. Org. Lett. 2018, 20, 6298 .

[68] Sherwood, T. C.; Li, N.; Yazdani, A. N.; Murali Dhar, T. G. J. Org. Chem. 2018, 83, 3000.

[69] Kammer, L. M.; Rahman, A.; Opatz, T. Molecules 2018, 23, 764.

[70] Fu, M.-C.; Shang, R.; Zhao, B.; Wang, B.; Fu, Y. Science 2019, $363,1429$.

[71] Zuo, Z.; MacMillan, D. W. C. J. Am. Chem. Soc. 2014, 136, 5257.

[72] Lang, S.; O’Nele, K.; Tunge, J. J. Am. Chem. Soc. 2014, 136, 13606

[73] Li, J.; Lefebvre, Q.; Yang, H.; Zhao, Y.; Fu, H. Chem. Commun 2017, 53, 10299.

[74] Yang, H.; Tian, C.; Qiu, D.; Tian, H.; An, G.; Li, G. Org. Chem. Front. 2019, 6, 2365

[75] Guo, J.; Wu, Q.; Xie, Y.; Weng, J.; Lu, G. J. Org. Chem. 2018, 83, 12559

[76] Ren, L.; Cong, H. Org. Lett. 2018, 20, 3225.

[77] Wang, C.; Guo, M.; Qi, R. Shang, Q.; Liu, Q.; Wang, S.; Zhao, L.; Wang, R.; Xu, Z. Angew. Chem., Int. Ed. 2018, 26, 15841.

[78] Zuo, Z.; Ahneman, D. T.; Chu, L.; Terrett, J. A.; Doyle, A. G.; MacMillan, D. W. C. Science 2014, 345, 437.

[79] Johnston, C. P.; Smith, R. T.; Allmendinger, S.; MacMillan, D. W. C. Nature 2016, 536, 322.

[80] Zuo, Z.; Cong, H.; Li, W.; Choi, J.; Fu, G. C.; MacMillan, D. W. C. J. Am. Chem. Soc. 2016, 138, 1832

[81] Oderinde, M. S.; Varela-Alvarez, A.; Aquila, B.; Robbins, D. W.; Johannes, J. W. J. Org. Chem. 2015, 80, 7642

[82] Luo, J.; Zhang, J. ACS Catal. 2016, 6, 873.

[83] McTiernan, C. D.; Leblanc, X.; Scaiano, J. C. ACS Catal. 2017, 7 , 2171.

[84] Suen, L. M.; Wang, C.; Hunter, D. N.; Mitchell, H. J.; Cnverso, A.; ElMarrouni, A. Synthesis 2018, 50, 3177.

[85] Kautzky, J. A.; Wang, T.; Evans, R. W.; MacMillan, D. W. C. J. Am 
Chem. Soc. 2018, 10, 6522.

[86] Zhnag, H.; Zhang, P.; Jiang, M.; Yang, H.; Fu, H. Org. Lett. 2017, 19, 1016.

[87] Mao, R.; Frey, A.; Balon, J.; Hu, X. Nat. Catal. 2018, 1, 120.

[88] Liang, Y.; Zhang, X.; MacMillan, D. W. C. Nature 2018, 559, 83.

[89] Rueda-Becerril, M.; Mahe, O.; Drouin, M.; Majewski, M. B.; West, J. G.; Wolf, M. O.; Sammis, G. M.; Paquin, J. F. J. Am. Chem. Soc. 2014, 136, 2637.

[90] Ventre, S.; Petronijevi, F. R.; MacMillan, D. W. C. J. Am. Chem. Soc. 2015, 137, 5654.

[91] Wu, X.; Meng, C.; Yuan, X.; Jia, X.; Qian, X.; Ye, J. Chem. Com- mun. 2015, 51, 11864

[92] Lang, S. B.; Cartwright, K. C.; Welter, R. S.; Locascio, T. M.; Tunge, J. A. Eur. J. Org. Chem. 2016, 3331.

[93] Davies, J.; Angelini, L.; Alkhalifah, M. A.; Sanz, L. M.; Sheikh, N. S.; Leonori, D. Synthesis 2018, 50, 821.

[94] Hu, D.; Wang, L.; Li, P. Org. Lett. 2017, 19, 2770.

[95] Fawcett, A.; Pradeilles, J.; Wang, Y.; Mutsuga, T.; Myers, E.; Aggarwal, V. K. Science 2017, 357, 283.

[96] Jiang, M.; Yang, H.; Fu, H. Org. Lett. 2016, 18, 1968.

[97] Jin, Y.; Yang, H.; Fu, H. Chem. Commun. 2016, 52, 12909. 